\title{
«HIPPOLYTVS»: ESTUDIO DE UN NUEVO MOSAICO DEL GÉNERO DE PESCA Y CON INSCRIPCIÓN PROCEDENTE DE COMPLUTUM ALCALÁ DE HENARES, MADRID
}

\author{
S. RASCÓN MARQUÉS \\ J. POLO LÓPEZ \\ Centro de Estudios Arqueológicos y Etnográficos/TEAR \\ J. GÓMEZ PALLARÉS \\ Universitat Autónoma de Barcelona \\ A. MÉNDEZ MADARIAGA \\ Consejería de Cultura CM
}

La Casa de Hippolytus es un edificio de la periferia de Complutum, cuya funcionalidad aún por definir, apunta hacia un uso lúdico. Se presenta aquí el mosaico que pavimenta una gran sala de distribución, mosaico ejecutado por dos equipos distintos, uno de raigambre hispánica, autor del campo geométrico, y otro de formación norteafricana encargado de la confección del emblema, y del que conservamos una inscripción que indica la autoría del mosaico y la relación de dependencia del maestro musivario respecto a la familia de los Anios: «Hipólito, que pertenece a los Anios, ha teselado este mosaico». El emblema reproduce una escena de pesca, del tipo que es habitual en el Norte de Africa en los siglos III y IV. La cronología que proponemos para el mosaico es la misma que para el resto de la edificación en esta su segunda fase: finales del siglo III o siglo IV d.C., lo que coincide con la cronología detectada en la mayor parte de los establecimientos complutenses que se han excavado.

The House of Hippolytus is a building at Complutum outskirts, whose functional characters is yet unknown, but can be of leisure kind. The floor of the principal hall is a mosaic made by two different teams: one of hispanic roots, that do the geometric ground, and the other of african source, that do the emblema. This one has one text with the author's name and his relationship with the Anios family: «Hipolito, who belong to the Anios, has made this mosaic». The emblema shows a picture about fishing, from the common African kind of III and IV centuries. We purpose for the mosaic the same date that for the rest of the building in this phase: end of III century or IV century A.D., like the one detected at most of the carved Complutum buildings. 


\section{EL CONTEXTO HISTÓRICO Y ARQUEOLÓGICO}

\section{1. La ciudad de COMPLVTVM.}

Hemos denominado Casa de Hippolytus a un edificio de considerable tamaño y lujosa decoración que se encuentra en la periferia de la ciudad de Complutum. Esta, que se configura como una ciudad de nueva planta en la década de los 60/70 del siglo I de nuestra era, está ubicada en la fértil vega del Henares, junto a la confluencia de este río con el Camarmilla.

Las primeras noticias de las que tenemos referencia para la ciudad de Complutum nos las proporcionan las llamadas fuentes geográficas. Tito Livio narra la huida de Sertorio hacia Valencia, en el año 75 a.C., aunque en este momento el núcleo habitado, que sirve de lugar de paso, se sitúa todavía en el Cerro de San Juan del Viso, y seguramente sería un castro influenciado por la cultura ibérica, aunque con una suficiente importancia como entidad poblacional. El traslado de la ciudad vieja indígena, parece producirse en torno a los años 60/70 d. C., con lo que se configura en la vega del Henares como Nova Urbs en la citada fecha, según se puede desprender del estudio de los materiales hecho por sus excavadores (FERNÁNDEZGALIANO RUIZ, 1.984a:352; RASCÓN-MÉNDEZ, en prensa). En el s.I d.C. es el único núcleo urbano nombrado por Plinio (III, 24) como ciudad estipendiaria del Convento Cesaraugustano. La fecha del cambio de status jurídico, de ciudad peregrina a municipium, no se conoce con precisión, aunque debió de ocurrir en el año 74 d.C. por medio del Edicto de Vespasiano (GONZÁLEZ-CONDE PUENTE, 1.985:134). A partir de este momento se nos descubre como un emplazamiento de cierta entidad, con una prosperidad que sin duda se relaciona con su buena situación en la red viaria hispanorromana, siendo hoy por hoy por otra parte el único punto claro que aceptan todos los investigadores al tratar de articular la red de comunicaciones romana en la Comunidad de Madrid.

Más abundantes, aunque al igual poco extensas, son las noticias de las fuentes antiguas de índole específicamente itineraria. Para nuestro caso disponemos del Itinerario de Antonino, en el que se menciona a Complutum en dos ocasiones, como una de las mansiones en la vía que conectaba Emerita Augusta con Caesaraugusta (ROLDÁN HERVAS, 1.975:85-57).

Otra fuente del siglo VII, el Anónimo de Rávena, recogiendo datos de los siglos III y IV, también menciona a la ciudad de Complutum, describiendo la segunda parte del trazado de Emerita a Caesaraugusta, entre Complutum y Emerita, y que completa la primera de Caesaraugusta a Complutum (ROLDÁN HERVAS, 1975: 127-129).

De carácter epigráfico conservamos diferentes miliarios que sitúan a Complutum en el entramado viario hispanorromano, y que hablan de diversas reparaciones de sus vías. Para el tramo comprendido entre Titulcia y Complutum tenemos uno de Trajano, así como otro para el tramo entre Complutum y Segontia, del emperador Decio. Otro apareció en el despoblado de Valtierra (Arganda, Madrid), fechado en el 101 d.C. (FERNÁNDEZ-GALIANO, 1976: 59-60). Una cuarta noticia sobre otra piedra itineraria es trasmitida por Fita $(1.885: 52)$ y anotada por Hübner (CIL II, $n^{\circ} 4.913$ ), aunque en la actualidad no sabemos nada sobre el texto, y su paradero es desconocido.

En el Bajo Imperio comienzan a aparecer diferentes noticias trasmitidas por los autores cristianos que atestiguan el continuo poblamiento de la ciudad romana. Aunque el lugar exacto de su emplazamiento no se sabe con certeza, parece probable que por razones religiosas se trasladasen al «campo laudable», lugar en el que se enterró a mártires cristianos y que coincide con el embrión de la Alcalá de Henares bajomedieval. Sin embargo, hasta el siglo VI hay grupos que habitan en las ruinas de la antigua ciudad, reutilizando los materiales de edificios públicos (MÉNDEZ-RASCÓN, 1.989: 179 y ss.). Así, Aurelio Prudencio Clemente, poeta cristiano nacido en 348 d.C. y muerto después del 405 d.C., recoge en su obra Peristephanon una lista de mártires de diferentes ciudades hispanas y entre ellos nombra a «..Justo y Pastor de Complutum.» muertos en la persecución de Diocleciano (GROSSE, 1.959: 374) .

De Paulino de Nola, poeta cristiano natural de Burdeos, nos dicen las fuentes que a su paso por Hispania se detuvo en diferentes ciudades como Complutum, Caesarangusta, Tarraco y Barcino, también que poseía una villa en los alrededores de Complutum (GROSSE, 1.959). Esta noticia es de suma importancia ya que equipara, en cierta medida, a estas cuatro ciudades, por lo que suponemos que a finales del s.IV, Complutum debió de ser todavía un centro comercial, administrativo y religioso que gozaría de indudable atractivo. Este dato se corrobora arqueológicamente en las excavaciones de las suntuosas casas romanas del casco urbano y del entorno complutense, fechadas en su mayoría en época bajoimperial.

Con la desarticulación del Imperio y la presencia de los visigodos, Complutum pasa a ser un nudo estratégico de primer orden en el control de las principales vías de comunicación (MÉNDEZ-RASCÓN, 1.989: 185-186). A principio del siglo VII es convertida en Sede Episcopal de la cual tenemos noticias desde el año 631, fecha en la que los obispos de Complutum firman el Concilio que legitima la usurpación de Sisenando (GROSSE, 1.947:288). A partir del 636 y hasta el 693 tenemos atestiguada la presencia de diferentes obispos, como es el caso de Davila, Acisclus, Gildemerus y Spassandus, representando a la Sede Episcopal de Complutum en el Concilium Toletanum (GROSSE, 1.947: 291).

De la ciudad romana conservamos diversas edificaciones, entre ellas una serie de casas privadas y un conjunto de edificios públicos que comprenden una basílica, unas termas y un 


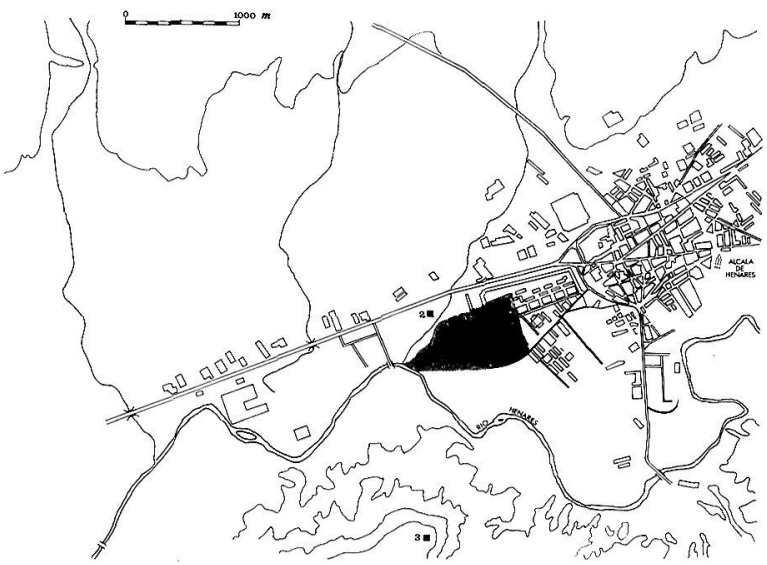

Fig. 1.- Situación del área urbana de Complutum (1), la Casa de Hippolytus (2) y el núcleo de época augustea del cerro del Viso (3).

ninfeo. Las fases cronológicas que se han podido establecer para dicho complejo son ilustrativas de la cronología de la ciudad enteral:

- la fase I se corresponde con la fundación del nuevo asentamiento, en época de Claudio - Nerón.

- la fase II se inicia a finales del siglo III o principios del IV, y en ella se reconstruyen los edificios públicos y se levantan de nueva planta los privados. Esta fase se prolonga hasta principios del siglo $\mathrm{V}$, momento en que se abandona la ciudad y sobre todo se pierde el uso que la define como tal. Hasta bien entrado el siglo VII aún se constata una presencia marginal, que responde a reutilizaciones de espacios.

\section{I.2. La casa de HIPPOLYTVS.}

La casa de Hippolytus es un asentamiento que se levantaría a unos 300 metros de lo que consideramos el perímetro urbano de Complutum (fig. 1). En este sentido, se enmarcaría dentro de lo que podemos denominar «cinturón norte», constituido por una serie de espacios suburbiales de distinta funcionalidad que supone la ubicación de determinados servicios y viviendas en la única zona que permite tal expansión, ya que el río Henares y los abruptos cerros de su margen izquierda evitan la posibilidad de expansión hacia el Sur.

El edificio se encuentra en proceso de excavación, habiéndose intervenido hasta la fecha en una superficie de $1.700 \mathrm{~m}^{2}$ de $\operatorname{los} 5.800 \mathrm{~m}^{2}$ totales.

\footnotetext{
' En el texto de RASCON Y MÉNDEZ (en prensa) que constituye la memoria de excavaciones de la zona de los edificios públicos complutenses se trata extensamente el tema.
}

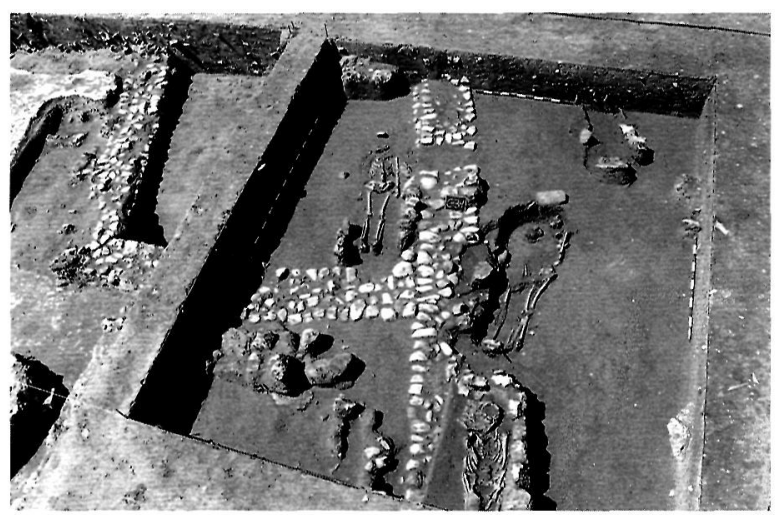

Lám. 1.- Sepulturas de la última fase de ocupación del yacimiento.

Su cronología tiene una buena constatación arqueológica en la estratigrafía, que nos ha deparado niveles prerromanos, casi totalmente arrasados por los posteriores: así hay una presencia marginal de materiales del Hierro II que documentan una ocupación humana de esta cronología, pero no aportan más información sobre la naturaleza del emplazamiento.

La presencia romana se estructura en dos fases, que se corresponden con dos edificaciones diferentes. La primera es coetánea a la fundación de la ciudad, y está bien fechada por la excavación de un vertedero con materiales que remiten preferentemente a los años centrales del siglo I de nuestra era. La segunda tiene una cronología menos precisa, que arranca desde la segunda mitad del siglo III o principios del IV. Dentro de ella se pueden distinguir diversas subfases que afectan a la estructura del edificio y a la funcionalidad del diseño originario. De hecho, algunos años antes de la fecha del abandono definitivo, el empleo de los espacios interiores no tenía ninguna relación con la concepción primitiva de sus propietarios y arquitectos y en las zonas nobles o lúdicas se instalaron sepulturas y hogares (lám. 1).

Para el objetivo del presente estudio nos interesa incidir sobre todo en esta segunda fase, que es la que ha deparado la casi totalidad de las estructuras conservadas. El edificio no está aún totalmente excavado, y el área abierta coincide con una serie de habitaciones de funcionalidad termal (fig.2, lám.2).

Un pasillo al que se accede por unas escaleras descendentes nos lleva a una gran habitación central de $75 \mathrm{~m}^{2}$, que configura un distribuidor en torno al cual se organizan una serie de estancias. En esta habitación se halló el mosaico objeto del presente trabajo, compuesto por una serie de escenas geométricas que rodean y enmarcan un emblema con una escena de pesca. El emblema, contraviniendo la norma general de la musivaria romana, no es central, sino que se encuentra en la esquina SE y desde ella se accede, por medio de unas escaleras facturadas en opus signinum, a una piscina de 1,20 m de 


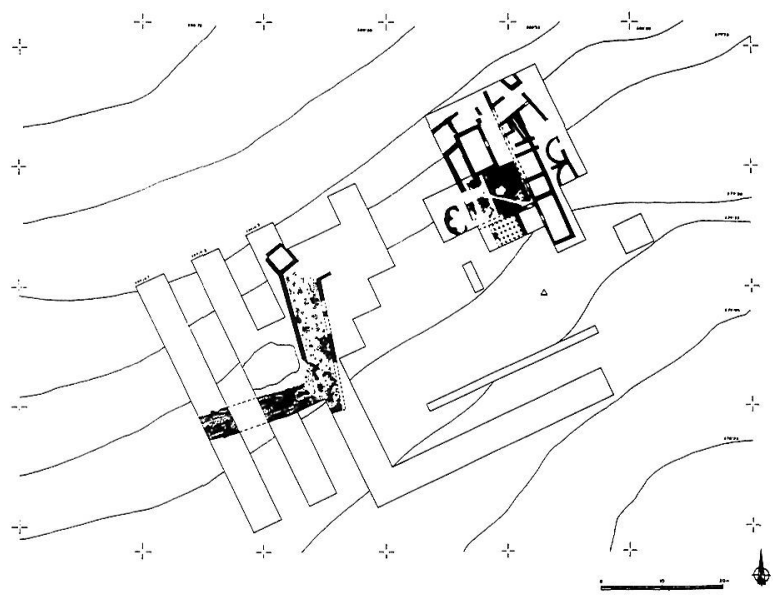

Fig.- 2.- Planta general de la Casa de Hippolytus al finalizar la campaña de 1.991 .

profundidad (lám. 3). La aparición de este tipo de escenas y motivos se relaciona en la mayoría de los yacimientos con construcciones termales y en otros de más reducidas dimensiones con piletas, fuentes y piscinas. Estos motivos aparecen en el siglo II d. C . en África Proconsular, aunque su desarrollo en la musivaria hispanorromana se produce en el siglo III d.C. (BALIL y MONDELO, 1985:256).

Esta piscina de agua fría, se halla pavimentada con otro mosaico, más sencillo en su composición y ejecución, pero de indudable interés arqueológico. Las paredes de esta estancia, que alcanzan en la actualidad 1,20 m de altura, están profusamente decoradas con pinturas murales, que remiten a escenas paisajistas.

Al Sur de la piscina se ubica una sala de forma y dimensiones rectangulares, excavada sólo parcialmente. Conserva al

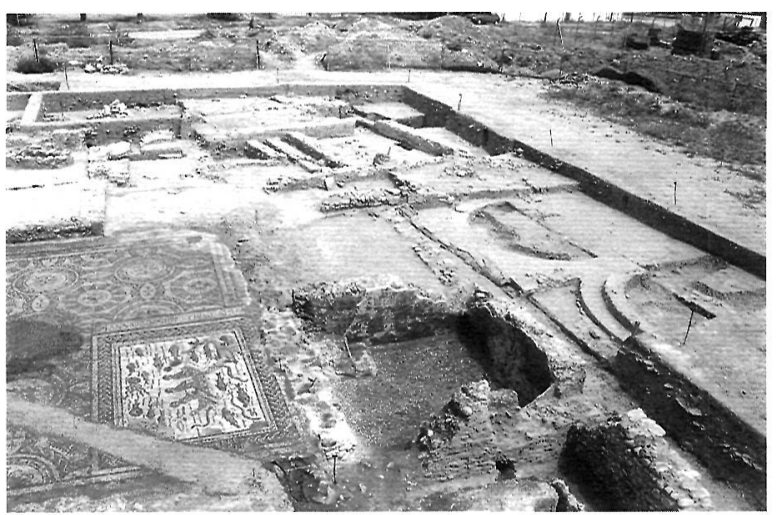

Lám. 3.- La piscina de agua fría.

igual que las habitaciones anteriormente descritas un pavimento de opus tessellatum de fondo blanco y con teselas negras que lo salpican. Gracias a la documentación de los sistemas de desagüe hemos podido precisar la funcionalidad de esta sala, que ha resultado ser unas letrinas.

$\mathrm{Al}$ Oeste encontramos otra constituida por una estancia principal, con hypocaustum y pavimentada con mosaico, rematada por una estructura menor donde se documenta un gran pozo que baja hasta el nivel freático.

Al Norte de la sala principal se levantaba una habitación rectangular, en la cual encontramos un sofisticado sistema constructivo a base de tubos de arcilla cocida (tubi fictile) con cuello abocinado y forma cilíndrica. Este diseño permitiría embutir estos elementos en diversas posiciones y unirlos con mortero, con lo que se crearía un sistema abovedado de cubierta (ADAM, 1.984: 192; también BRODRIBB, 1.987: 87) (lám.4). Para este caso tenemos algunos ejemplos en Piazza Armerina, en la bóveda de San Vital en Rávenna, aun-

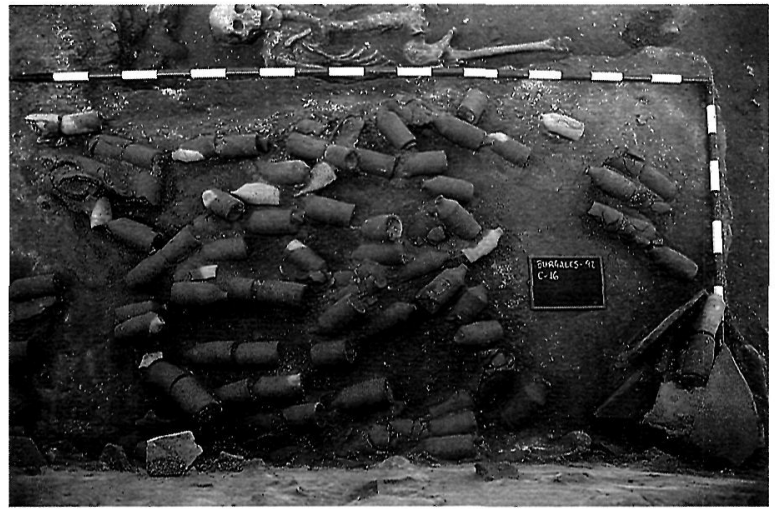

Lám. 4.- Derrumbe de tubuli fictile. 


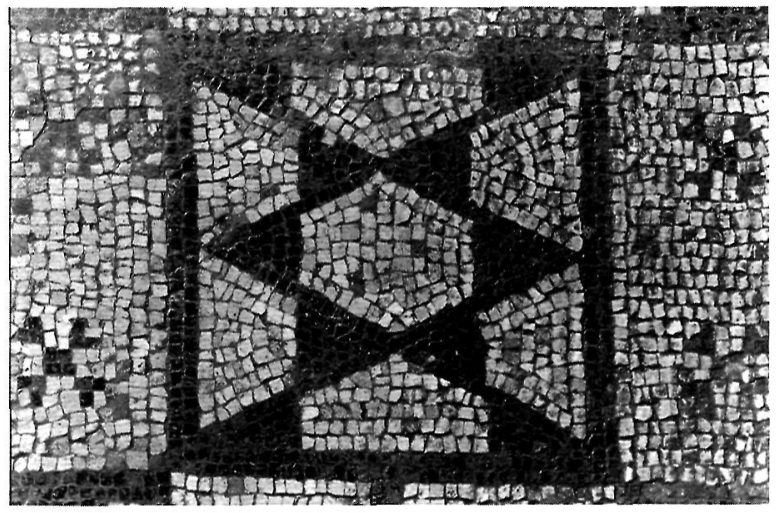

Lám. 5.-Motivo de «relojes de arena».

que son comúnmente hallados en Africa del Norte, como en la habitación XX de Leptis Magna, así como en diferentes estructuras termales de Dougga y Bulla Regia.

Al Este del pasillo de acceso encontramos una estancia con muros de opus caementicium y alzado de adobe, en la que se han podido documentar, entre el derrumbe de la misma, algunos fragmentos de mosaico parietal, formado por teselas de pasta vítrea de pequeño tamaño y diverso colorido.

Además de las estructuras descubiertas en este área de la excavación, que afecta aproximadamente a la mitad oriental de la casa, una serie de zanjas de 5 por $50 \mathrm{~m}$ ha servido para localizar lo que suponemos el límite occidental del edificio, articulado con un pavimento de canto rodado que hay que interpretar como un camino de acceso, cuya cronología se remonta a la primera fase del edificio.

Faltando por excavar aproximadamente la cuarta parte de la planta de este edificio, es difícil pronunciarse sobre su tipología. Las estructuras excavadas hasta ahora son de uso termal (incluso la gran sala de distribución se inclina suavemente para que el agua vierta dentro de la piscina), y si a esto unimos la presencia de un innegable lujo decorativo, que añade a los mosaicos la existencia de una estatua mutilada de Diana y restos de capiteles corintios, habremos de pensar en un pequeño complejo lúdico, quizá perteneciente a algún grupo o asociación de carácter semiprivado, si bien hasta el final de la excavación del edificio y el definitivo proceso de los datos resultantes no será posible un pronunciamiento definitivo.

\section{EL MOSAICO DE LA ESTANCIA DE DISTRIBUCION}

\section{1. Descripción.}

El mosaico que nos ocupa pavimenta una gran habitación rectangular de 7,50 por 8,70 metros, habitación que hemos definido como una sala de distribución. Esta se complementa con una piscina de agua fría, situada al Oeste, y a la que se accede por medio de tres peldaños.

No todo el mosaico se corresponde con una estancia en sí misma, ya que en la parte Oeste del mismo, una franja de 2,70 $\mathrm{m}$. que recorre la habitación de $\mathrm{N}$ a $\mathrm{S}$, se configura como un pasillo. Por tanto tenemos el siguiente esquema a la hora de describir los pavimentos:

- Mosaico del pasillo.

- Mosaico de la estancia.

Dos zanjas de expolio, excavadas para arrancar las tuberías metálicas que surtían a las piscinas, recorren la sala: la primera de $\mathrm{N}$ a $\mathrm{S}$, justo entre los dos mosaicos; la segunda atraviesa el mosaico de la estancia en diagonal, cortando buena parte del campo geométrico.

\section{1.1. Mosaico del pasillo.}

A. Banda de enlace: sólo se conserva una parte de la misma en el lado Norte y otra en el Oeste. La unión con el mosaico de la estancia ha desaparecido por completo. De la banda de enlace norte se conserva una anchura máxima de 23 $\mathrm{cm}$. De la Oeste $10 \mathrm{~cm}$. Ambas son de color crema.

B. Retícula continua 1, de 1,50 por 3,10 metros. Resuelta a base de sucesiones de una sola tesela negra sobre fondo blanco. En el centro de cada cuadrado, una florecilla en tramos con pétalos de bordes escalonados.

C. Retícula continua 2, de 1,63 por 3,65 metros conservados, idéntica a la anterior de la cual la separa una orla que curiosamente no la rodea, sino que se superpone al dibujo por el lado Este.

D. Orla de retícula continua, 2. De $10 \mathrm{~cm}$ de ancho. Compuesta por dos hiladas simples de teselas negras (RGDG 137), y la orla en sí misma, del tipo de «greca fraccionada» (RGDG 247).

E. Sucesión de cuadrados flanqueados por rectángulos. Entre cada serie, una banda de enlace en la que se cambia la razón, pasando a tener la composición un rectángulo y dos cuadrados menores. Los rectángulos siempre tienen como decoración una pareja de florecillas negras con fondo blanco. Los cuadrados pequeños alternan dos posibilidades distintas: la primera con cuadrados negros que giran $45^{\circ}$ dentro de los blancos y con una tesela blanca en su interior. La segunda, una florecilla blanca con fondo negro.

De los cuadrados principales conservamos dos decoraciones, ambas con negro sobre fondo blanco: una de ellas con un campo de «relojes de arena» que determina la creación de una estrella de seis puntas (lám.5). La otra, con un aspa formada por la intersección de dos cruces que giran $45^{\circ}$, la una respecto a la otra. Las que constituyen la diagonal tienen sus brazos terminados en punta.

F. Sucesión de cuadrados. Muy deteriorados, se aprecian dos flores y dos aspas, también en negro sobre fondo blanco. 

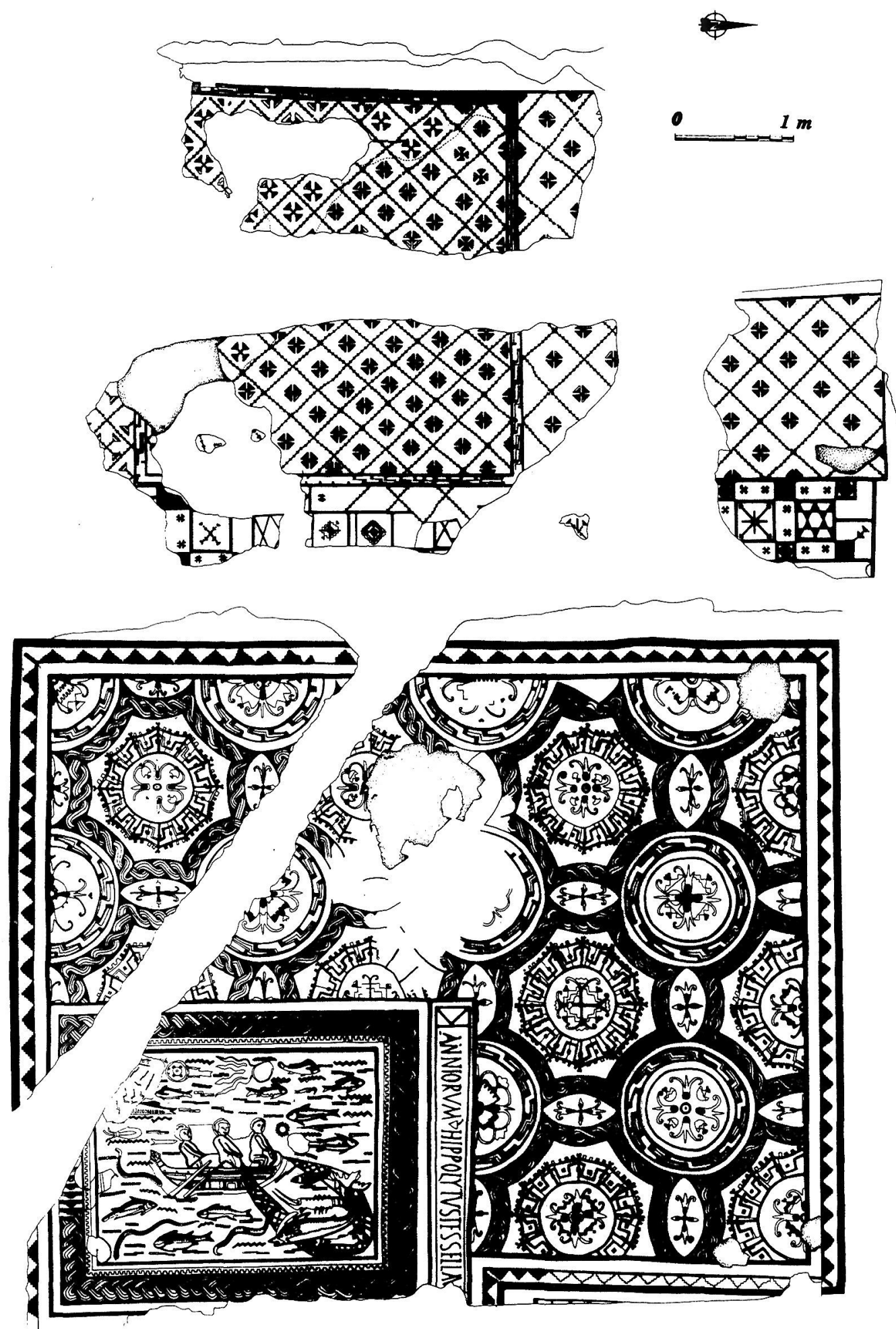

Fig. 3.- Plano del mosaico de la estancia de distribución. 


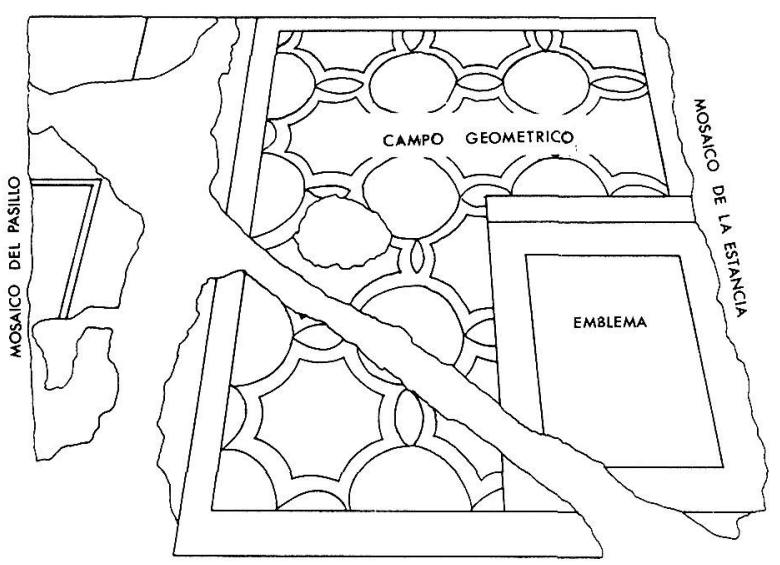

Fig. 4.- Croquis del mosaico de la estancia de distribución.

\section{1.2. Mosaico de la estancia (fig. 3 y 4).}

G. Banda de enlace. Conserva un ancho de $35 \mathrm{~cm}$ por el Norte y el Oeste. A 3,30 metros de la esquina NO, un umbral en blanco y negro.

H. Marco. Constituido por:

- Un listel negro de $8 \mathrm{~cm}$ y cuatro teselas (RGDG 140).

- Una línea de triángulos denticulados, de $14 \mathrm{~cm}$ (RGDG 161).

- Una banda blanca de $8 \mathrm{~cm}$ y cinco hileras de teselas.

- Una hilada negra de $3 \mathrm{~cm}$ y tres teselas (RGDG 139).

I. Campo geométrico. Dispuesto en $\langle V\rangle$ en torno al emblema. Lo constituyen un total de ocho filas de medallones, octogonales curvilíneos en las filas impares y circulares en las pares. En los dos casos hay un óvalo entre cada dos medallones. Cada figura, sea un medallón o un óvalo, está orlado por una cenefa de cable de dos cuerdas (RGDG 203) y cinco teselas, con colores negro, rojo, amarillos y crema respectivamen-

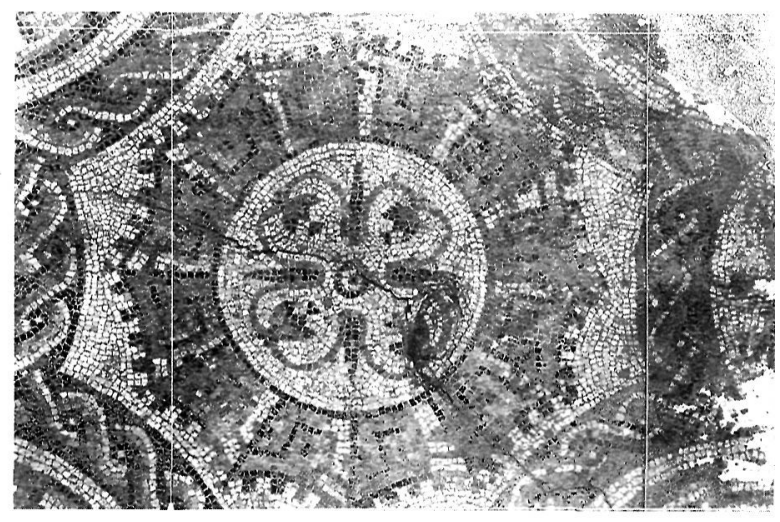

Lám. 6.- Medallones hexagonales.

te. El esquema de los medallones hexagonales es el siguiente: sobre fondo blanco, una orla de torreones a colores verdes y amarillos, que forman un dodecágono al exterior y un círculo al interior. Dentro, un motivo floral (lám.6). En los circulares, sobre fondo crema una cenefa de «greca fraccionada» (RGDG 247), de tres filas de teselas rojas, amarillas y cremas. Dentro un listel circular de una sola tesela negra. En el centro de la circunferencia, un motivo floral (lám.7). Los motivos florales que aparecen son siempre de cuatro hojas que se superponen sobre cuatro lóbulos, variando en cada medallón la forma de estos, que pueden ser escalonados $\left(\mathrm{n}^{\circ} 5,8,13,14,17\right.$ y 18), lobulados $\left(\mathrm{n}^{\circ} 1,2,3,4,9\right.$ y 12) o suplirse por cuatro florecillas de menor tamaño ( ${ }^{\circ} 6,7$ y 15). En cada medallón varía la combinación de los colores, que son siempre negros, ocres, grises y rojos.

Con respecto a los óvalos apuntados, el motivo que se inscribe en ellos es siempre el mismo: flores de lis de dos hojas que se cruzan con otras dos hojas perpendiculares a las primeras y que representan sendos capullos de flor (lám.8). Las

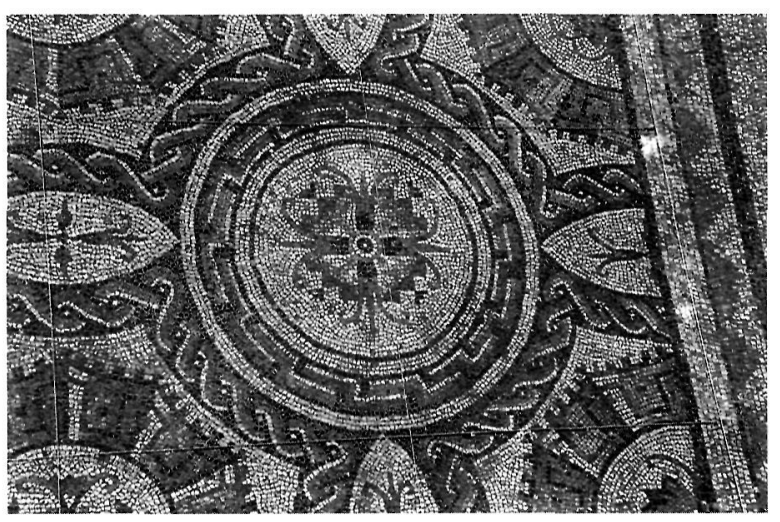

Lám. 7.- Medallones circulares.

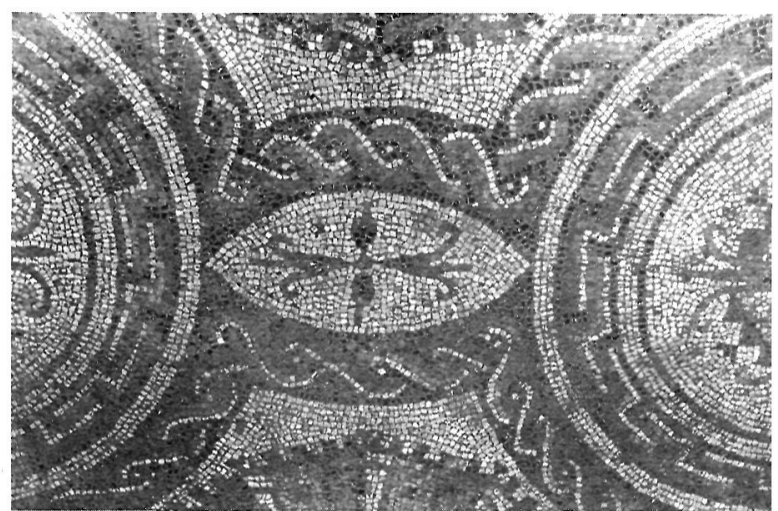

Lám. 8.- Ovalo apuntado. 


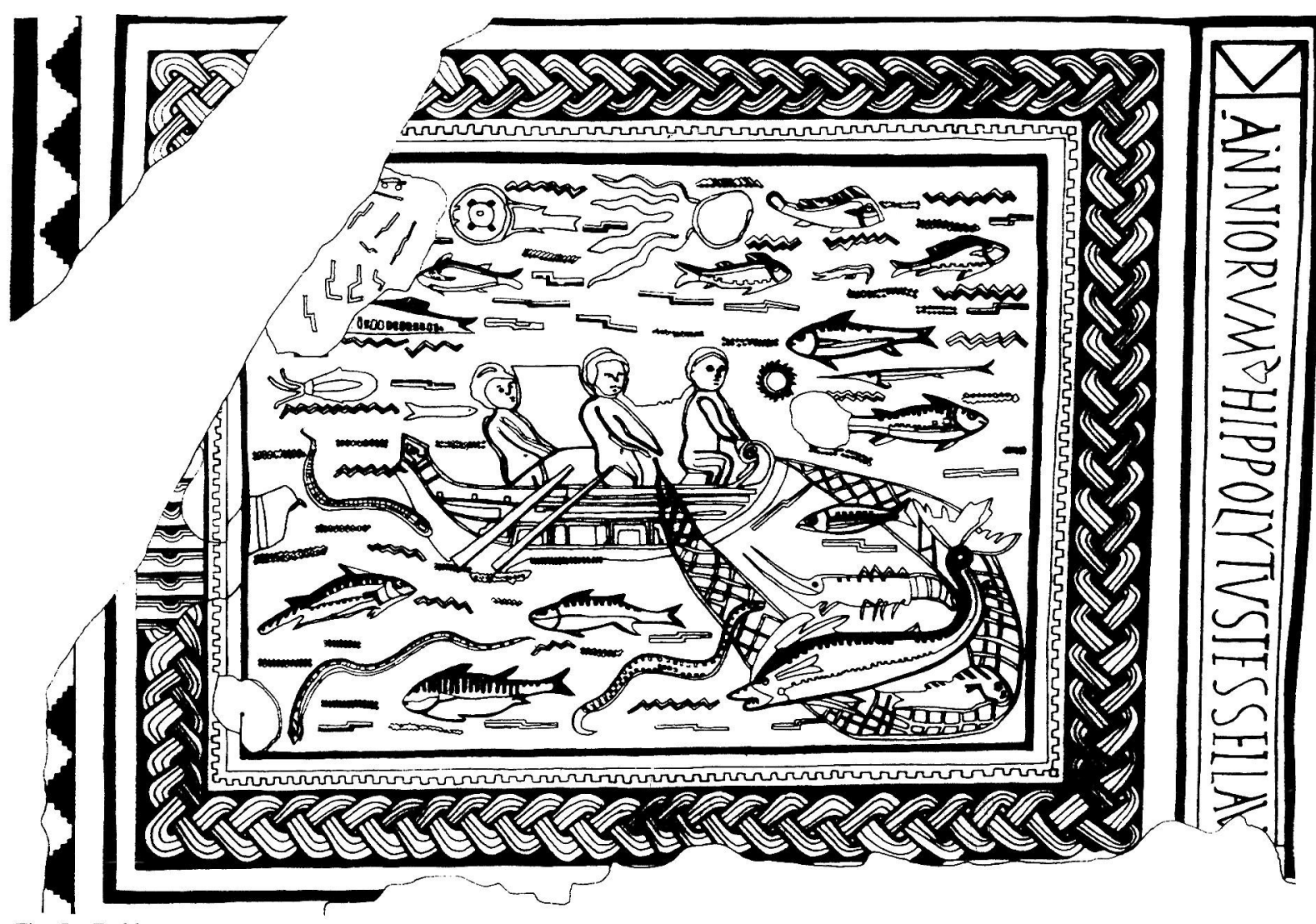

Fig. 5.- Emblema.

flores son de color rojo, mientras que los tallos conservan un color negro.

J. Emblema (fig.5, lám.9): contraviniendo la norma habitual de la musivaria romana, el emblema se sitúa en la esquina SE de la habitación, afrontada a la puerta que da acceso a la piscina de agua fría.

El emblema consta de las siguientes partes:

- Inscripción.

- Marco.

- Cuadro.

La inscripción se encuentra en el lado $\mathrm{N}$ del emblema, perpendicular al punto de vista del mismo. En ella puede leerse el texto ANNIORVM (hédera) HIPPOLYTVS TESSELLAV[IT], enmarcado probablemente entre dos triángulos rojos (sólo se conserva el izquierdo) y con dos listeles negros separados por una banda crema. La inscripción se comentará más extensamente en el siguiente punto de este estudio.

El marco se compone de:

* Listel negro de dos teselas (RGDG 138).

* Banda crema de cinco teselas.

* Orla de cable de cuatro cuerdas, cada una de cinco teselas negras, rojas, amarillas, cremas y negras (RGDG 197).
* Borde crema que contiene una línea de taqueado roja (RGDG 144).

* Listel negro de dos teselas (RGDG 138).

El cuadro representa una escena de pesca, en la cual tres erotes, que navegan en una barca, recogen sus redes rodeados de una abundante fauna marina, en la que se ven representados un total de veintidós animales, que enumeramos a continuación (fig. 6):

1: Pulpo (Octopus vulgaris).

2: Pulpo (Octopus vulgaris).

3: Túnido sin determinar.

4: Túnido sin determinar.

5: Langosta

6: Túnido sin determinar.

7: Túnido sin determinar.

8: Erizo de mar

9: Pez espada o Aguja (Belone Belone).

10: Túnido sin determinar.

11: Túnido sin determinar.

12: Langosta

13: Delfín

14: Túnido sin determinar. 


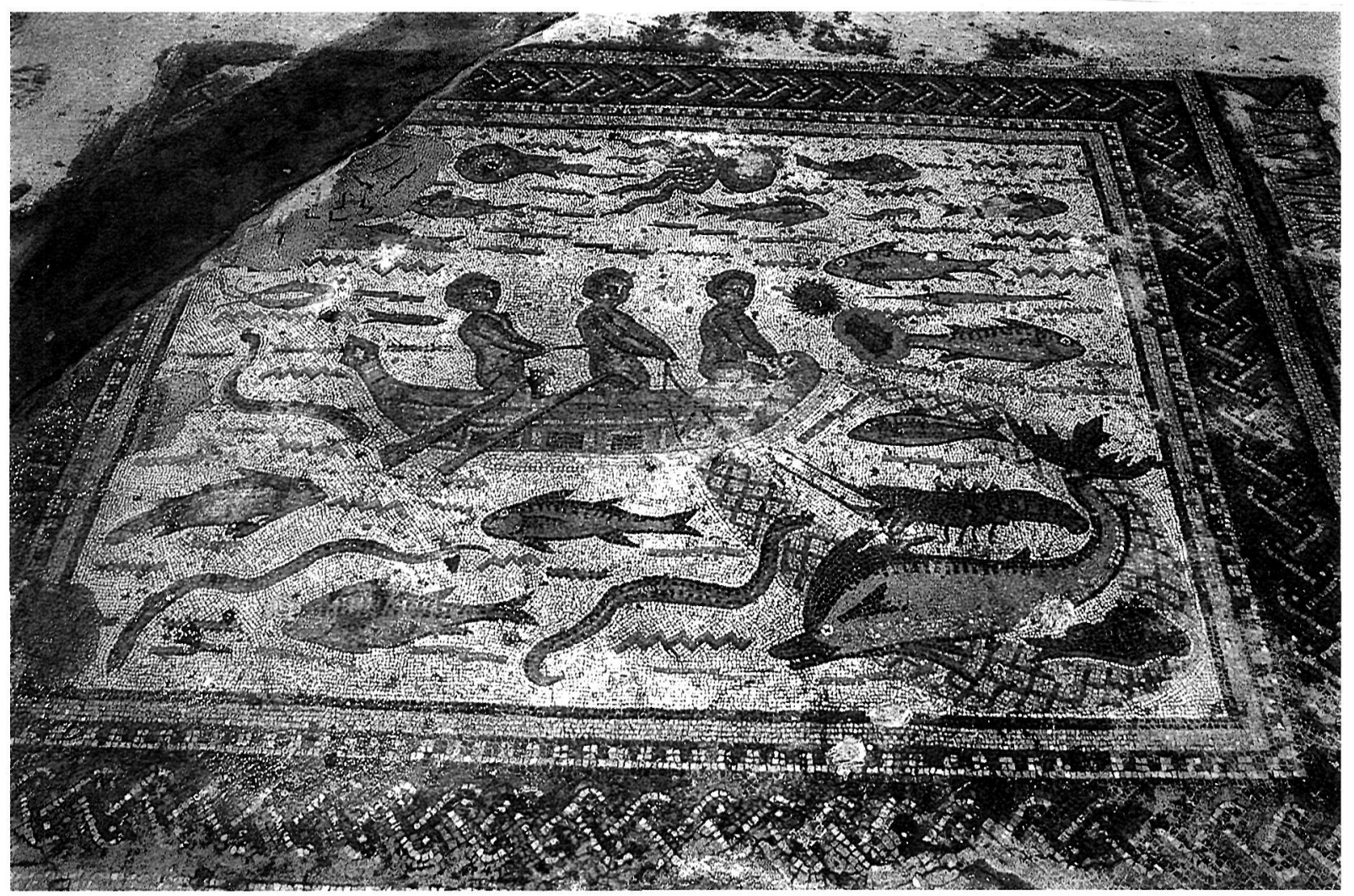

Lám.9.- Emblema.

15: Morena (Muraena Helena).

16: Túnido sin determinar.

17: Túnido sin determinar.

18: Morena (Muraena Helena).

19: Mero

20: Morena (Muraena Helena).

21: Túnido sin determinar.

22: Sepia (Sepia Officinalis).

23: Túnido sin determinar.

24: Túnido sin determinar.

Como se verá, se distinguen por su tratamiento hasta seis tipos diferentes de túnidos, que no pueden identificarse con especies concretas.

Las gamas cromáticas que se emplean para los diferentes animales son las siguientes:

* Pulpo: rojo oscuro, rojo, amarillo, crema y blanco.

* Túnidos: rojo oscuro, rojo, amarillo, crema, blanco y negro, en el que definiremos como tipo 1 . Verde (lomo), negro (contorno y bandas atigradas en el lomo), rojo, rojo oscuro y amarillo (panza y branquias) y blanco (ojos), para el tipo 2. Rojo, amarillo, blanco (ojo) y negro para el tipo 3. Amarillo (lomo y panza), rojo oscuro, blanco (ojo) y negro, para el tipo 4. Verde (panza y lomo), negro y amarillo para el 5. En este caso nos falta la parte delantera del animal, que ha sido obje-

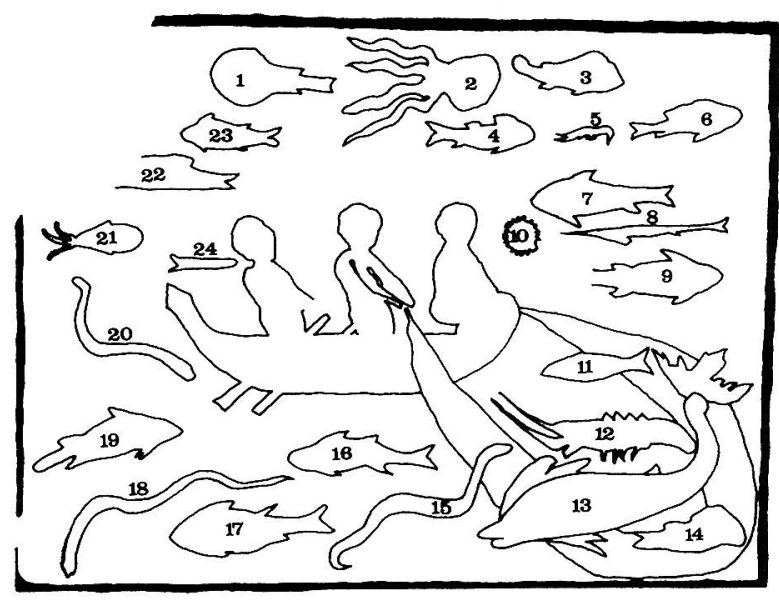

Fig. 6.- Croquis con la identificación numérica de los peces del emblema. 
to de una restauración posterior. Verde (lomo), rojo oscuro, amarillo y gris (bandas longitudinales en lomo y aleta), negro y blanco, para el tipo 6 .

* Langosta: rojo oscuro, rojo, amarillo, blanco (ojo) y negro. La pequeña $\left(n^{\circ} 5\right)$ se resuelve solamente por medio de amarillo, rojo y rojo oscuro.

* Mero: verde (lomo), negro, rojo oscuro (branquias), rojo (panza), amarillo y crema.

* Murena: negro (lomo), amarillo y crema (ambos para la panza), rojo oscuro y pardo (para señalar los lunares y rayados de las escamas).

* Delfín: verde (lomo), negro (contorno, sombra sobre el lomo, aleta dorsal), rojo, rojo oscuro y amarillo (aletas y boca) y blanco (ojos y dientes).

* Pez espada: verde (lomo), amarillo y rojo (panza), blanco (ojo) y negro.

* Calamar: amarillo, blanco y verde.

* Erizo: rojo, rojo oscuro y amarillo (en el disco) y negro (contorno y púas).

En todos los casos en que aparece representado, el ojo del animal es totalmente frontal, resolviéndose por medio de un disco blanco con un punto negro, con una única tesela en el centro.

La barca que lleva a los tres erotes es del tipo vegeiia o placida, de casco muy curvo, con la popa rematada por una voluta, y la proa con un apéndice triangular. La barca es de color amarillo y su borda con bandas verticales rojas. Se dibuja además una serie de líneas complementarias en color pardo, que enmarcan a los bordes verticales, pero también se disponen horizontalmente a lo largo de la borda. Como complemento aparecen los colores azul claro (en una banda que adorna la proa) gris y crema.

Los tres erotes están absortos en su oficio, recuperando la red que han lanzado y en la cual se debaten el delfín, la langosta y dos túnidos. El fondo de la red se resuelve con teselas de color crema, que destacan sobre el blanco del fondo, y la retícula alterna el pardo y el negro. Los tres personajes se nos presentan en un campo visual equivalente al llamado «plano americano», de rodillas hacia arriba, todos en tres cuartos y tirando de la red con ambas manos. Los colores con que se resuelve son rojo oscuro, rojo, crema, amarillo, rosado, blanco y negro. Los personajes se dibujan con esquemática sencillez, en la que el artesano ha prescindido de los detalles anatómicos, articulando el bulto de torso, brazos y piernas por medio de un degradado cromático. Como es habitual en la musivaria romana, el resto se resuelve mediante dos líneas negras horizontales para la nariz y la boca. En los ojos se bordean con tesela negra toda la cuenca.

El fondo del cuadro, que representa el mar, es blanco, en contraste con el color crema que sirve de fondo al resto del mosaico. Las olas se sugieren por medio de líneas quebradas y en zig-zag que alternan siempre una pareja de colores entre los verdes, grises, pardos y negros.

\section{II.2. Estudio.}

\section{II.2.1. Motivos geométricos.}

El campo de círculos y octógonos curvilíneos que se combina por medio de óvalos es especialmente interesante por ser poco frecuente en Hispania, y en general en todo el Imperio, al contrario de lo que ocurre con los campos de hileras de círculos, de los que existen varios ejemplares hispanos (por ejemplo en Los Quintanares de Soria - BLÁZQUEZ y ORTEGO, 1.983: 25 y ss., 16 -, Castilleja del Campo -BLÁZQUEZ, 1982: 37, f 3 y 4- o Itálica en Sevilla - BLANCO, 1978: 51 y ss, 1. 61-77, y sobre todo africanos, donde esta composición es muy frecuente desde inicios del s.II en adelante, contando con un amplio catálogo que recoge ejemplares de numerosas ciudades tunecinas.

Nuestro tema compositivo lo encontramos en Mérida, en los mosaicos del solar de la Antigua Ermita de La Piedad y del Parador, donde a diferencia de lo que ocurre con el ejemplar complutense, los octógonos superan en tamaño a los círculos (ÁLVAREZ MARTÍNEZ, 1990: 27 y ss, 1. 1-5, f. 1; también p. 49,1.21-22). Su excavador se remite a los estudios de Stern, que en base a los paralelos de Nora, Esquilino, Ostia y Sousse, por un lado y, los de la Villa di Patti de Sicilia, y la Casa de Aion en Antioquía, por otro considera esta composición característica del Mediterráneo Occidental, donde se desarrollaría sobre todo a lo largo del siglo III d.C., cronología en la que se enmarcan los cuatro primeros.

En la misma Complutum contamos también con otro mosaico, el de Júpiter y Leda, que utiliza una composición parecida a la nuestra: un campo de hileras en las que alternan círculos y octógonos curvilíneos, donde la articulación entre los distintos elementos se realiza por medio de exágonos irregulares e igualmente curvilíneos (fig.7). Fernández-Galiano (1984: 213) hace derivar este dibujo de aquel que alterna círculos y cuadrados de pico (RGDG 339) y propone una fecha del siglo IV d.C. para su diseño, aunque sólo en base a otros dos paralelos que ya cuentan con esta cronología. Sin embargo nos reiteramos en que el mosaico de Júpiter y Leda presenta una composición sólo parecida a la de Hippolytus, que es singular en lo que se refiere a la musivaria complutense conocida hasta la fecha, tanto en la misma ciudad, como en los edificios de su entorno, como es la Villa del Val (MÉNDEZRASCÓN, 1989b: 50 y ss.). También novedosos en este entorno cultural y geográfico son los motivos florales que rellenan cada uno de los medallones, así como las murallas inscritas en cada octógono, apreciándose en los primeros una fuerte inspiración pictórica.

Por el contrario, el resto de los motivos geométricos son 


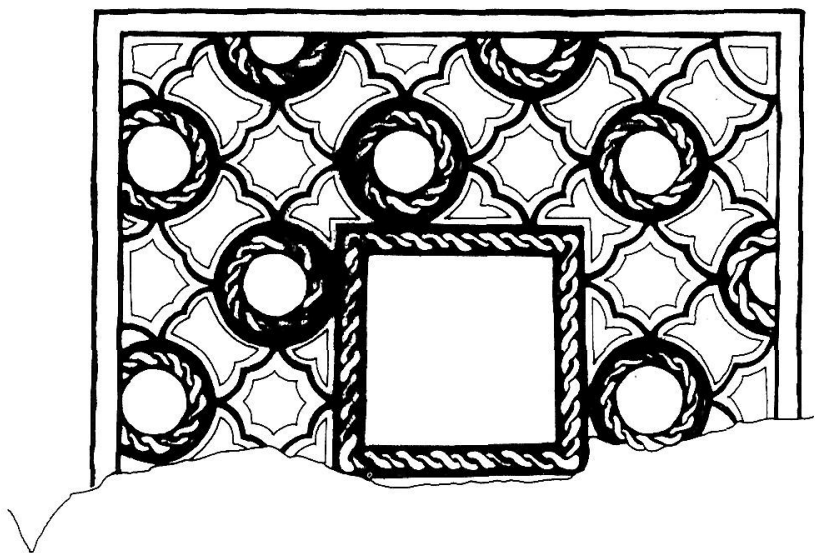

ESQUEMA COMPOSITIVO DEL MOSAICO DE ZEUS Y LEDA

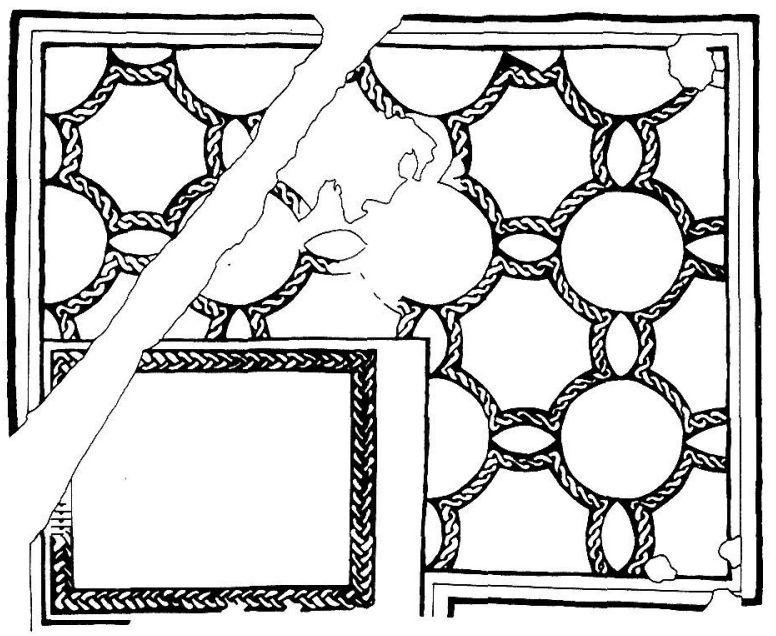

ESQUEMA COMPOSITIVO DEL MOSAICO DE HIPPOLYTYS.

Fig.-7. Comparación de los esquemas compositivos de los mosaicos de Hippolytus y Zeus y Leda.

frecuentes tanto en el ambiente complutense, como en la musivaria romana en general.

La línea de taqueado (RGDG 144) aparece ya en los mosaicos de Cupidos 1 y 2 y de Júpiter y Leda, los tres en Complutum. Balil (1958: 353 y 1969: 103-113) y FernándezGaliano (1984: 130-131) han rastreado su presencia respectivamente en el resto del Imperio y en Hispania, sin poder concluir una cronología clara, aunque constatando lo usual de su empleo tanto en el Mediterráneo Occidental como en la propia Península.

La línea de triángulos denticulados (RGDG 161) podemos encontrarla en el complutense mosaico de Cupidos 1. Es un motivo que puede rastrearse hasta época helenística, y ya en el mundo romano registró una extraordinaria difusión que se inicia en la Italia del siglo I d.C., y continúa durante los tres siglos siguientes, afectando además a todo el territorio imperial. Remitimos al estudio de Cupidos l para la enumeración de los correspondientes paralelos (FERNÁNDEZ-GALIANO, 1984: 129-130).

Con respecto a los cables, los de dos cuerdas (RGDG 194) aparecen en todas las casas complutenses excavadas, así como en la villa romana del Val, cosa que no podía dejar de ocurrir, teniendo en cuenta que se trata probablemente del motivo geométrico más empleado por los musivarios romanos. El cable de cuatro cuerdas (RGDG 197) lo encontramos en los motivos figurados del mosaico de Baco.

\section{II.2.2. Mosaico del pasillo.}

La retícula continua es uno de los temas más frecuentes de la musivaria de la parte oriental del Imperio. Posiblemente su origen esté en los reticulados sobre opus signinum que proliferan en los últimos años de la República y primeros del Imperio, en el siglo I d.C. Su cronología, refiriéndonos ya al opus tessellatum se remonta al siglo II d.C. para las provincias del Mediterráneo Oriental, mientras que para la parte Occidental no se documentan hasta época severiana, con alguna excepción un tanto dudosa. El tema ha sido muy bien estudiado por FERNÁNDEZ-GALIANO (1984: 46 y ss.) con respecto al mosaico de Aquiles, y a él nos remitimos para su estudio detallado y para el catálogo de paralelos.

Los ejemplares occidentales son pocos comparados con los que proceden del Mediterráneo Oriental. Pese a ello existe una importante serie en el Norte de Africa, donde gran parte de las ciudades romanas de las actuales Túnez y Argelia cuentan con al menos un ejemplar: Utica, Nabeul, Timgad, Sousse, Maktar, Acholla, Djebel Oust, Bulla Regia y Thuburbo Maius.

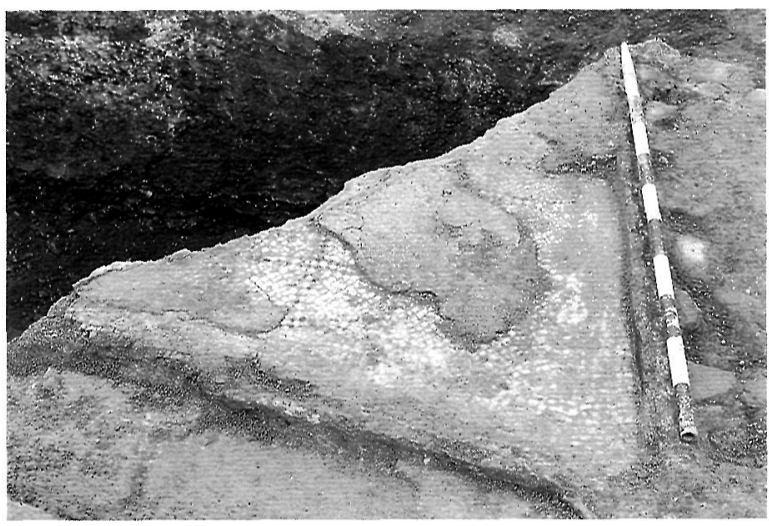

Lám. 10.- Mosaico de retícula de la villa del Val, antes de su restauración. 


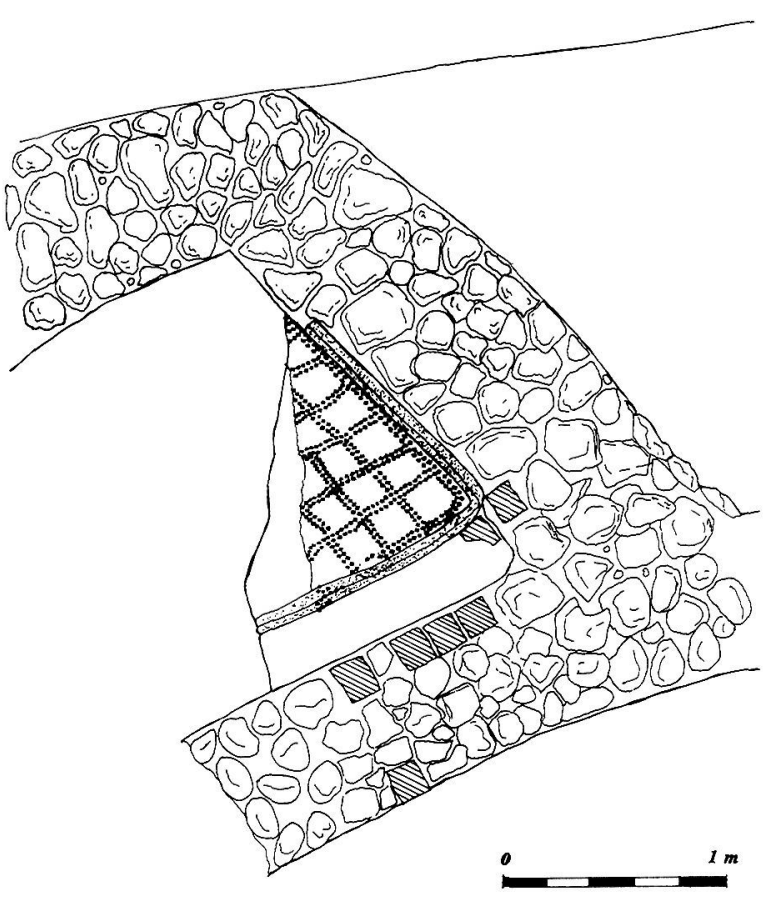

Fig. 8.-Mosaico de retícula procedente de la villa del Val.

Sus cronologías se mueven entre finales del siglo II y el siglo IV d.C.

En Hispania los mosaicos con retícula son los siguientes:

* Tossa del Mar (Gerona), con doble línea de teselas, muy tardío (FERNÁNDEZ-GALIANO, 1984: 47).

* Villa de Torre Llauder (Mataró), también con doble línea de teselas, del s.IV (FERNÁNDEZ-GALIANO, 1984: 47.

* Los Quintanares (Soria), con doble línea de teselas, del siglo III o IV (BLÁZQUEZ y ORTEGO, 1983: 19-20.

* De Mérida conocemos también varios ejemplares: el de la calle Félix Valverde Lillo, con las retículas de una sola tesela, que combinan con las de cuatro en el mismo pavimento, y fechado por su excavador con respecto a diversos paralelos de los siglos II al IV d.C. (ÁLVAREZ MARTÍNEZ, 1990: 106 y ss., f. 11, 1. 52-53). Es un buen paralelo para el mosaico de Hippolytus, ya que el relleno de las retículas de una tesela se soluciona en ambos casos por medio de una florecilla de pétalos con los bordes escalonados. Encontramos igualmente otro ejemplar de mediados del siglo IV en la calle Holguín, así como en la Casa del Anfiteatro, de finales del siglo III, y la Prolongación de Pedro M ${ }^{a}$ Plano (ÁLVAREZ MARTínEZ, 1.990: respectivamente, 69 y ss., f. 6, 1. 32-38; y p. 75).

En el entorno complutense lo encontramos en dos ocasiones: el mosaico de Aquiles (FERNÁNDEZ-GALIANO, 1984: 38) y un mosaico reticulado que presentamos por vez primera

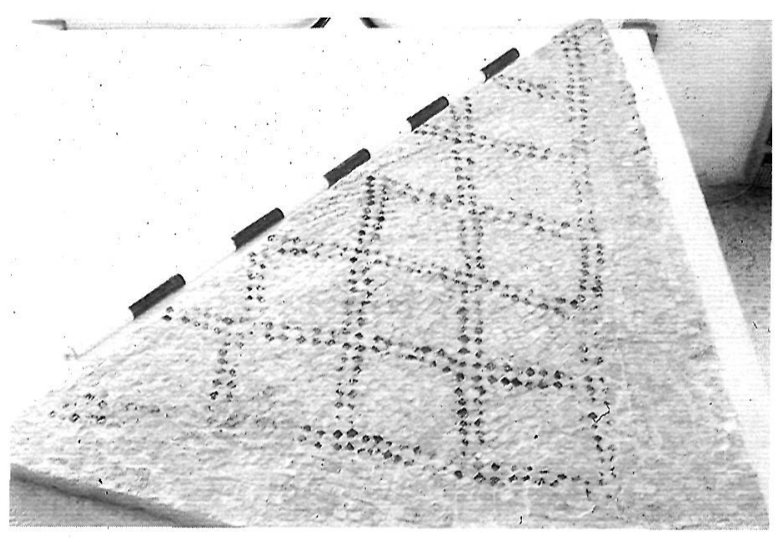

Lám. 11.- Mosaico de retícula de la villa del Val, una vez restaurado.

en esta publicación de la villa romana del Val (láms. 11 y 12 , fig.8) siendo el primero de línea simple de teselas por oposición a la línea doble del segundo.

El campo de relojes de arena lo encontramos repetido por todo el Imperio. Sólo en Hispania aparece en los siguientes yacimientos:

* Mérida, en tres mosaicos: el del Parador (de finales del siglo III d.C. o principios del IV d.C.), asociado también a un campo de círculos y exágonos (ÁLVAREZ MARTíNEZ, 1990: 47 y ss.). El de la Casa del Mitreo, del siglo II (BLANCO, 1978: 39). El de la calle Holguín, de mediados del siglo IV (ÁLVAREZ MARTÍNEZ, 1990: 69-79, f. 6, 1. 32-38).

* En la villa de Liédena, el mosaico de la habitación n ${ }^{\circ} 3$, del siglo III (BLÁZQUEZ-MEZQUIRIZ, 1985: 44 y ss., 1.28 y 29).

\section{II.2.3. El emblema.}

\section{II.2.3.1. Los orígenes del género de peces y pesca.}

La pesca y la representación de fauna y paisajes marítimos están muy vinculados al arte del mundo mediterráneo ya desde tiempos muy arcaicos, remontándose al menos a la cultura cretense. Sin embargo, a la hora de buscar una inspiración directa para este género, desarrollado abundantemente por pintores y mosaistas romanos, hay que aludir a la pintura de «marinas» helenísticas, que desde el siglo II a.C. sería adoptada por artistas itálicos dando lugar a un buen número de creaciones (BALIL-MONDELO, 1985: 251-256. También BALIL, 196263, 123-127. Igualmente, PICARD et alii, 1977). Además existen una serie de mosaicos que marcan hitos dentro de este proceso de adaptación y que serían atribuibles a una escuela itálica de tradición helenística o simplemente a una tradición hele- 


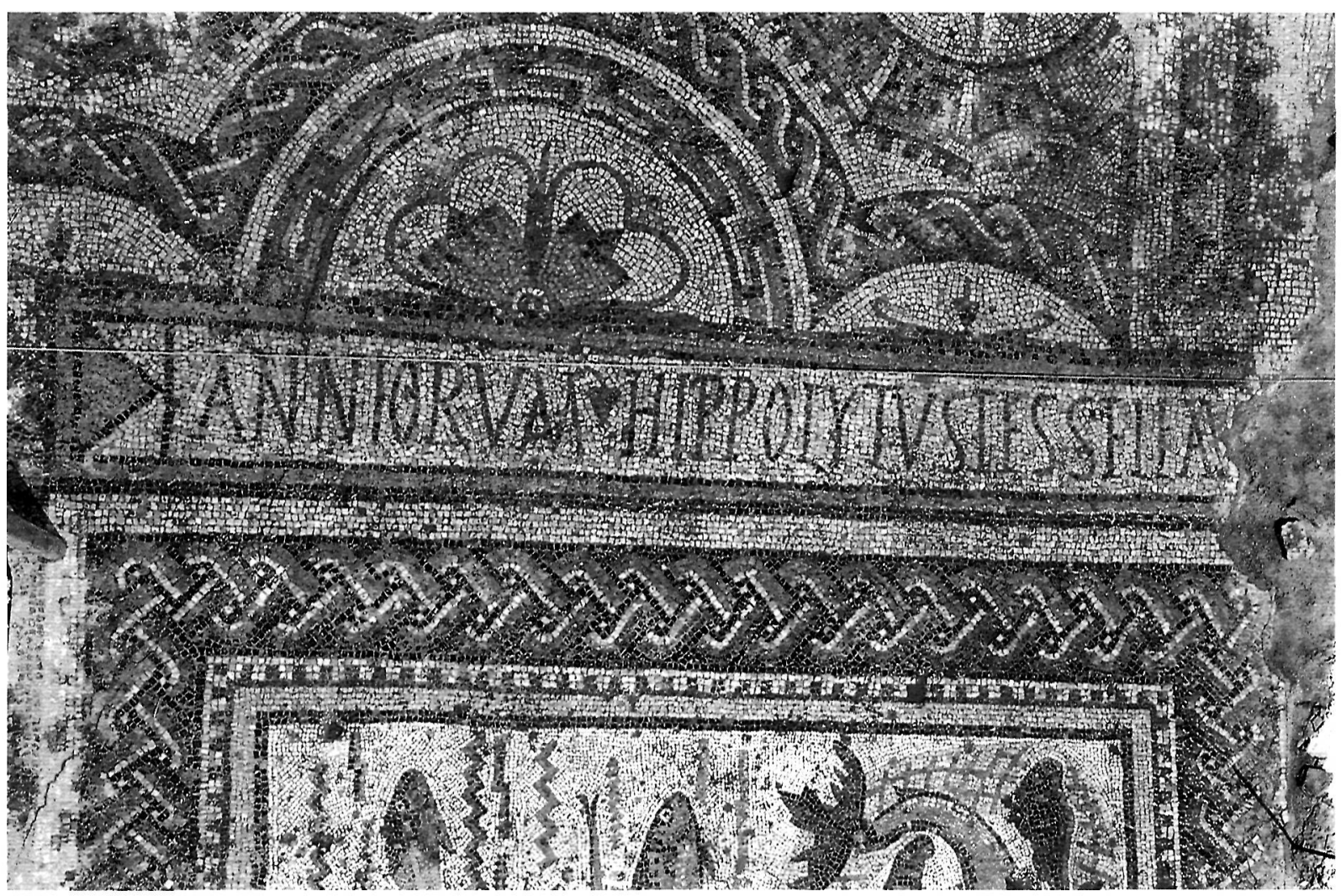

Lám. 12.- Inscripción del emblema.

nística común que existiría en diversos puntos del Mediterráneo. La temática no se refiere solamente a los ambientes marinos, sino que abarca todo un catálogo de motivos que incluye en los peces, la pesca, los paisajes marítimos y fluviales, el thiasos y las escenas nilóticas, en general todo aquello que ilustra una vida idílica e imaginaria con el mar, las costas y los ríos, con claros paralelos en los contenidos poéticos que maneja la literatura de la época, como ya señaló Balil a propósito del mosaico de Ampurias (BALIL, 1960).

Entre los primeros ejemplares que documentan el paso de este género a la musivaria se encuentra el mosaico de Palestrina, del siglo II a.C. (GULLINI, 1956), así como el conjunto de los emblemata pompeyanos del siglo I d.C. (PERNICE, 1936: 148 y ss. También PALOMBI, 1980), todos ellos atribuibles a una escuela itálica. De época e inspiración helenística, no necesariamente itálicos en su origen, son los de Pérgamo, Delos o Tripolitania (FERNÁNDEZ-GALIANO, 1984: 102).

Tenemos por tanto un desarrollo del género en la propia Italia, que continuará a lo largo de los siglos I y II d.C., transformándose en general de la policromía a la técnica del blan- co y negro. Al mismo tiempo contamos con una tradición helenística que afecta al Mediterráneo en general. Es difícil precisar cuál de los dos, si no son ambos, sirve de modelo para la eclosión del tema marítimo en los mosaicos del Africa Proconsular desde el siglo II al siglo IV d.C., consolidando una tradición con la que se relaciona directamente nuestro mosaico complutense.

II.2.3.2. El mosaico de Hippolytus y los mosaicos de peces y pesca en Hispania.

La mayoría de los paralelos del género de marinas que podemos encontrar para nuestro mosaico se hallan en el Norte de Africa, donde hay cartones que se enmarcan dentro de la misma línea. Sin embargo, la fauna marina es también relativamente frecuente en mosaicos hispanos, ya sean bícromos o polícromos. A continuación recogemos una serie de ellos:

- El de la Casa de los Peces en Complutum, que pavimenta un impluvium. Es de época de Galieno, tiene una fuerte influencia de la técnica del blanco y negro y los peces son su único motivo figurado. La única especie que se reconoce es el 
delfín, pues la otra que se representa no deja de ser un estereotipo genérico (FERNÁNDEZ-GALIANO, 1984: 100-110).

- El del Camino Viejo de las Sepulturas de Balazote (Albacete) $)^{2}$, que representa una escena marítima con fauna mediterránea como pequeños peces, gasterópodos, moluscos y un delfín. También es visible parte de una embarcación. El mosaico pavimenta una estancia perteneciente a un complejo termal y es fechado por sus investigadores en el siglo III y IV d.C. (SANZ GAMO, 1987a: 55 y 1987b).

- El de La Cigarrosa (Orense), de finales del siglo III o principios del IV d.C., con representación de fauna marina. Pertenece a un complejo termal (ACUÑA, 1972).

- El de Osuna (Sevilla), con fauna y elementos paisajísticos marítimos y fluviales en blanco y negro. Se fecha en la primera mitad del siglo III d.C. (BLÁZZQUEZ, 1982: 84;1. 47).

- Gilena (Sevilla), con fauna marina en blanco y negro. Respecto a su cronología se ha propuesto una fecha del siglo II d.C. (BLÁZQUEZ, 1982: 37; F.5).

La Pineda (Tarragona), del segundo cuarto del siglo III d.C., con un nutrido catálogo de especies marinas (BALIL y MONDELO, 1985: 256).

- El de Toledo, que combina la fauna y el paisaje marino con escenas portuarias. Estaba pavimentando una fuente y se fecha en época tetrárquica (BALIL, 1962-63: 137).

- En Córdoba encontramos otro mosaico de similar funcionalidad que el anterior, en donde se representa el thiasos marino en blanco y negro. Su cronología es del siglo II d.C.(BALIL, 1962-63: 137).

Podrían añadirse algunos ejemplos más de mosaicos con tema marino, que por otra parte no saldrían de la tónica general, con repertorios de especies marinas que se desarrollan en la mayoría de los casos en blanco y negro o con una fuerte influencia de esta técnica, como es el caso de la Casa de los Peces de Complutum. Hay que destacar también la relación de estos motivos ornamentales con recintos relacionados con el agua, sean estos termas, impluvia o fuentes. En cambio el tema de la pesca no es demasiado frecuente, y de entre los reseñados solo está presente en el mosaico de escenas portuarias de Toledo. Así mismo hay que apuntar, por su evidente relación con el mosaico de Hippolytus, un ejemplar de Los Marroquíes Altos (Jaén), donde se representa a un erote que rema sobre su barca, motivo este frecuente en la musivaria romana, que entre sus paralelos cuenta con tres ejemplares de Carthago, Leptis Magna y Hadrumetum (BLÁZQUEZ, 1981: $60-61,1.47-48)$.

\footnotetext{
${ }^{2}$ Queremos agradecer muy sinceramente las facilidades prestadas por Rubí Sanz Gamo, directora del Museo de Albacete, que en todo momento atendió amablemente nuestras consultas sobre el complejo termal de Balazote.
}

II.2.3.3. El mosaico de Hippolytus y el género de pesca en el Norte de África.

El pleno desarrollo de este género, con una personalidad y unas características singulares y distintas en todo caso de la escuela «blanquinegra» itálica, tuvo lugar en el África Proconsular, donde se inicia en el siglo II d.C. para conocer su esplendor en el siglo III, perdurando en el IV y pudiendo encontrarse incluso en el VI. Durante este tiempo su abundancia en los edificios es muy amplia y sólo una primera vista a sus museos, inventarios y yacimientos nos permite encontrar dos ejemplares en Hippo Regius, dos en Thuburbo Maius $\left(\mathrm{n}^{\circ}\right.$ A 371 y 2804 IMB), tres en Althiburus (A 295, 176 y 392 IMB), tres en Dougga (2884, 2885 y 2886 IMB), uno en Sidi Abdallah, uno en Djemila, siete en Carthago (A 7, 338, 290, 2807, 2772, 3636 y 3648 IMB), cinco en Sousse (57095, 57158,57159 y 57204 IM), dos en Vthina y dos en Bulla Regia, todo ello sin pretender ser exhaustivos y sin considerar algunos temas de tipo marino que se alejan un tanto del mosaico de Hippolytus y la temática de peces y pesca, como puede ser el thiasos $^{3}$. Por otro lado a ésto habría que añadir los mosaicos de escenas marinas y erotes pescando de Piazza Armerina, para los que también se ha propuesto un origen africano (DUNBABIN, 1978: 201, 206 y ss.).

Pasando ya a comentar los diversos motivos de nuestra escena de pesca, tomaremos en primer lugar al trío de erotes que lanzan sus redes. Colocados en posición de tres cuartos, los personajes se resuelven con el esquematismo habitual que caracteriza la musivaria romana entre los siglos III y V: sendas líneas negras indican la nariz y la boca, y los ojos se consiguen marcando sus contornos. Los tres aúnan sus esfuerzos, tirando con ambas manos de la red llena de peces.

Si observamos uno de los mosaicos de Thuburbo Maius, procedente de la Casa del Carro de Venus ( $n^{\circ} 2804$ IMB, 299 CMT), encontraremos estas mismas soluciones en una de las tres barcas que evolucionan en medio de un mar plagado de peces: dos pescadores, situados en una posición de tres cuartos tiran con ambas manos de las redes. Las proporciones de los personajes son infantiles, aunque en este caso están vestidos con túnica. También el tipo de embarcación coincide con el mosaico complutense, siendo del tipo vegeiia o placida. La cronología propuesta nos lleva a una fecha post quem del 317 d.C. (CMT, II, 3: 84 y 87; f. 8; 1. XXXIV, XXXV y XXXVI).

La misma solución a la pesca con redes la vemos aplicada a una pareja de pescadores desnudos en un mosaico parietal de Sousse ( $n^{\circ} 57159$ IM) que adornan la piscina de una

${ }^{3}$ Los números de inventario del IMB se recopilan en YACOUB, 1970. Los del IM que se mencionan en el texto en FOUCHER, 1960. 


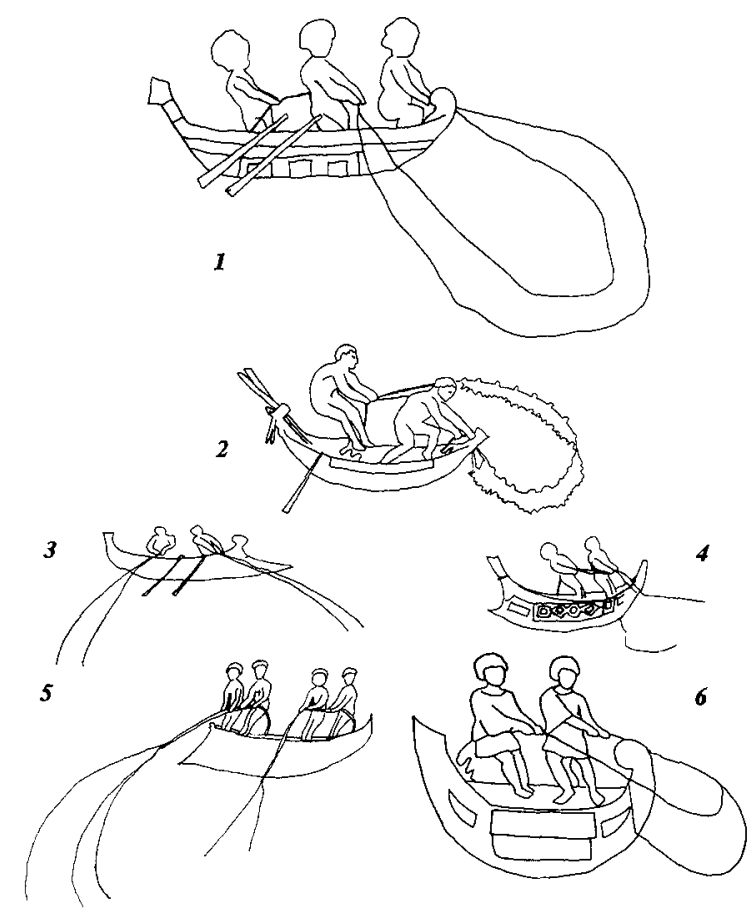

1. Mosaico de Hippolytus (Complutum); 2. Sousse, Lamina de Historia Natural, finales del siglo II d.C.; 3. Sousse, fimales del siglo III d.C.; 4. Utica, finales del siglo III o principios del IV d.C.; 5. Sidi Abdalla, siglo IV; 6. Thuburbo Majus, p.q. 317 d.C.

Fig. 9.- El conjunto de pescadores de Hippolytus comparado con los de Thuburbo Maius, Sousse, Sidi Abdallah y Utica.

casa, y que se fecha a finales del siglo III d.C. (FOUCHER, 1.960: 72-73; 1 XXXV C.). Otro tanto cabe decir del pavimento de los baños de Sidonius, en Sidi Abdallah, con cuatro pescadores rubios y desnudos, del siglo IV d.C. (YACOUB, 1970: f. 66; también DUNBABIN, 1978: pl. 50). Ya con un tratamiento algo distinto, pues cambian las posturas de los pescadores, que están resueltos con mayor realismo, aplicándose un completo estudio anatómico en cada caso, tenemos los mosaicos $n^{\circ} 57095$ IM de Sousse, de principios del siglo III d.C. (FOUCHER, 1960: 45; pl XXI), y el n 57204 , la magnífica «Lámina de Historia Natural», también de Sousse, ejecutada a finales del siglo II d.C. para una cámara funeraria pagana (FOUCHER, 1960: 91; pl XLVI.). También aparece la pesca con red en otro mosaico de ambiente nilótico donde, sin embargo, los pigmeos que la recogerían han desaparecido. Procede de Sousse $\left(n^{\circ} 57027\right)$ y se fecha a mediados del siglo III d.C. (FOUCHER, 1960: 9-11; pl. IV y V). De nuevo encontramos a una pareja de pescadores desnudos, que se nos enfrentan en una posición de tres cuartos y tirando de la red con ambas manos, en la Casa de la Cascada de Utica, del siglo II d.C. Nuevamente los erotes pescadores, desnudos sobre su barca, aparecen en una fuente de Bulla Regia, conservada in situ. Por último encontramos dos mosaicos de pesca en la Casa de los Laberii de Vthina, fechados por Dunbabin entre los años 160-180 d.C.

La embarcación del mosaico de Hippolytus entra en la categoría de barca de pesca, en concreto dentro del tipo de vegeiia o plácida $a^{4}$ A la hora de buscar un paralelo lo más exacto posible hemos de acercarnos de nuevo al mosaico de la Casa del Carro de Venus de Thuburbo Maius, donde las tres barcas representadas son casi idénticas a las nuestras, con la salvedad de que la proa se resuelve de otro modo, terminando ésta en un apéndice triangular perforado, mientras que en aquellas es simplemente apuntada. El apéndice perforado, un elemento práctico para remolcar la barca o simplemente atarla en su fondeadero, puede verse en los mosaicos n ${ }^{\circ} 57095$ y 57204 de Sousse, ya aludidos anteriormente, sobre barcas de tipo cymba (FOUCHER, 1960:36 y ss.; f.30-33).

En el mosaico de Hippolytus el paisaje ha desaparecido por completo, y el mar se reproduce utilizando líneas quebradas y en zig-zag, que rellenan el campo que los peces no han ocupado. Una característica de este género es precisamente el barroquismo decorativo con el consiguiente amontonamiento de los peces y los personajes en un espacio reducido. Pero frecuentemente los elementos paisajísticos están ausentes, y los artistas se limitan a sugerir la superficie ondulada del mar por medio de técnicas diversas, que además tienen una segunda misión muy importante: evitar que en el mosaico queden lugares y espacios sin ocupar. El método empleado para sugerir la superficie marina se ha empleado muchas veces para sugerir características comunes a escuelas concretas de mosaistas, este es el caso del taller de la Gallaecia al que Acuña y Balil atribuyen diversos mosaicos del NW hispano (ACUNA, 1972:474-476; BALIL, 1.965: 259-263) así como de la singularidad de la representación del agua en el complutense mosaico de la Casa de los Peces, donde los espacios vacíos se rellenan con teselas de colores rojizos y anaranjados (FERNÁNDEZ-GALIANO, 1984: 110). La técnica que se emplea en el mosaico de Hippolytus es la clásica, empleando líneas en zig-zag, que se combinan con líneas quebradas. Estas líneas heredan las que aparecen en los primeros mosaicos de este género, como el ya mencionado de Palestrina, donde son un apoyo para la gradación de colores

\footnotetext{
${ }^{4}$ La tipología de embarcaciones romanas en la iconografía puede encontrarse en DUVAL, 1.949. También en FOUCHER, 1957. Con todo, hay que advertir que es muy difícil precisar las tipologías de las embarcaciones que aparecen en las representaciones figuradas de la Antiguiedad, dado que muchas de ellas, y de forma particular vegeiia y placida admiten diferentes soluciones para la proa y la popa. El texto más reciente respecto a este tema es el de CHIC, 1993.
} 
que intenta representar las tonalidades del agua, siguiendo las técnicas pictóricas helenísticas. Ya a partir de finales del siglo II, las líneas rellenan la composición, representando un elemento paisajístico y convirtiéndose en el recurso único para evocar el entorno marino. La Lámina de Historia Natural de Sousse, es uno de los primeros mosaicos en que se reconoce esta técnica, pero a lo largo de los siglos III y IV, está presente en la totalidad de los mosaicos mencionados más arriba. Cronológicamente y como puede verse en los ejemplos anteriores su empleo se prolongó a lo largo de los siglos II, III y IV. Pese a ello, hay autores que quieren enfatizar su relación con el arte musivo del siglo III (FOUCHER, 1960: 11). Las líneas quebradas que aparecen junto a los zig-zag son menos frecuentes, y las hemos encontrado también en África, en dos piscinas de la Casa de la Cascada de Utica, acompañando también a las líneas de zig-zag, y con una cronología de finales del siglo II o principios del III.

Y llegamos por fin a los espacios marinos del mosaico de Hippolytus que protagonizan junto con los pescadores la escena del emblema. Ya hemos visto que el origen del género de pesca tiene una clara relación con las «marinas» helenísticas, donde el juego del reconocimiento de las especies representadas en la composición es un problema importante que el artista debe de afrontar a la hora de plantear su obra. En los mosaicos africanos sigue presente este interés, y los peces que desfilan por sus emblemata son especies concretas y reconocibles que pertenecen a unos repertorios comunes al patrimonio iconográfico del Imperio, pues pese a que estas obras conservan vivo el interés por el naturalismo de las pinturas helenísticas, ciertas formas de representar la realidad estaban notablemente estereotipadas.

Tomemos primeramente el caso de nuestro delfín. Siendo uno de los elementos de la fauna marina más representados de los mosaicos y pinturas romanos, es también uno de los que tienen una estereotipación más clara: así, y pese al mayor barroquismo cromático y anatómico del más estilizado ejemplar de Hippolytus podemos observar sus mismas características en el cercano mosaico de la Casa de los Peces de Complutum, a su vez con paralelos en Dueñas, Palencia, la villa de las Tiendas, Badajoz, y la misma Mérida, así como en otras artes decorativas del Bajo Imperio como son la escultura y la orfebrería. También a la misma tipificación, responden los delfines del tantas veces mencionado mosaico de la Casa del Carro de Venus, donde incluso la gama cromática es igual a la nuestra, así como los de La Pineda en Tarragona (BALIL y MONDELO, 1985: 86; 1. XXXV).

También en estos dos últimos mosaicos hay paralelos para las murenas, siendo además su estereotipación muy parecida a la que emplea Hippolytus. Aparece con mayor naturalismo en otros mosaicos como el $n^{\circ} 57095$ o el 57204 de Sousse (FOUCHER, 1960: 1. XXI y XLVI) o incluso en el mismo de Palestrina. Igualmente dilatada cronológicamente y siguiendo con una solución parecida, aunque menos acusado dado lo sencillo de su anatomía, es el caso del erizo de mar, que aparece en los referidos mosaicos de Sousse y también en las fuentes de la Casa de la Cascada de Utica. Otro tanto ocurre con el pulpo y la sepia, que en el ejemplar complutense responde ya a estereotipos consolidados, lejos del naturalismo de las pinturas helenísticas que inspiran su aparición en Pompeya y Palestrina.

Una última observación sobre la fauna nos lleva a considerar su gama cromática, con fondo blanco sobre el que se desarrollan los pobladores del mar en colores verdes, rojos y ocres, lo que una vez más nos lleva al mosaico de la Casa de Venus de Thuburbo Maius. El color verde, predominante en los cuerpos de los animales, es el mismo que aparece generosamente en los mosaicos tunecinos y que se extrae en el propio Golfo de Túnez, siendo por tanto un material de importación, si bien este extremo habrá de ser confirmado por el análisis petrológico de nuestro mosaico.

\section{II.2.3.4. El mosaico de Hippolytus y su contexto decorativo.}

No quisiéramos terminar esta parte del estudio sin incidir en el papel de nuestro mosaico dentro del programa decorativo que se refiere a la sala principal de distribución y su piscina de agua fría. Nuestro mosaico está concebido como un pavimento más para el interior de una fuente o piscina, como los casos mencionados de Bulla Regia o Thuburbo Maius, solo que en este caso se dispone en la entrada de la piscina y no dentro de ella por encontrarse esta a una cota inferior y en un recinto pequeño y cerrado, lo que evidentemente produciría una falta de luz y dificultaría su normal contemplación. Por ello dentro de la piscina se ha recurrido a un pavimento de opus tessellatum, con teselas de mayor tamaño y que sobre un fondo crema intercala alguna pieza ocre o roja, consiguiéndose un efecto ilusionista como el que puede observarse en el impluvium de la Casa de los Peces, donde la superficie del mar se trata por este procedimiento. En las paredes de la piscina, más iluminada que el fondo por la luz, que suponemos cenital, se desarrolla una pintura mural que ilustra un tema nilótico o alejandrino. A falta de la limpieza de gran parte de los fragmentos recuperados, sólo podemos hablar de la presencia de varios erotes y animales fantásticos, lo que nos remite a la misma tradición helenística que suministra el repertorio iconográfico del emblema (lámina 4).

\section{II.2.4. Cronología y conclusiones.}

La documentación arqueológica ha servido para conocer la ocupación del yacimiento desde mediados del siglo I d.C., pero es poco precisa a la hora de definir en qué momento se 

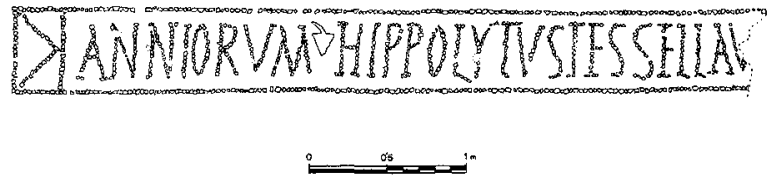

Fig 10.- Inscripción del mosaico de Hippolytus.

construyeron las estructuras que estamos comentando. Así pues, será el mismo mosaico el que nos permita aclarar la cronología de la Casa de Hippolytus.

Los motivos geométricos son poco explícitos en este sentido, dada la larga pervivencia de todos ellos. Se advierte sin embargo una mayor incidencia a lo largo del siglo III para el diseño del campo compositivo de hileras de octógonos y círculos, otro tanto ocurre con la retícula continua, de fuerte personalidad emeritense. El emblema es mucho más locuaz y aunque el género de pesca se inicia en el siglo II d.C., diversas razones nos llevan a proponer una cronología más baja.

En primer lugar, tenemos la técnica con que se representa el variado repertorio ictiográfico, llevándonos la estereotipación de los animales a paralelos como el de La Pineda, de finales del segundo cuarto del siglo III d.C., el de la Casa de Venus, con una fecha post quem del 317 d.C., o el de la Casa de la Cascada del siglo II d.C.

En segundo lugar, la concepción de la escena de pesca parece tener una inspiración común con el referido mosaico de Thuburbo Maius, aunque también es comparable con otros anteriores, como el $n^{\circ} 57159$ de Sousse, datado a finales del siglo III d.C., pero también posteriores como el de Los baños de Sidonius, del siglo IV d.C.

En tercer lugar se ha propuesto para las líneas de zig-zag una cronología del siglo III d.C., que debe entenderse, a nuestro juicio, en sentido amplio, pues aparece ya en el siglo II d.C. y se prolonga hasta el IV d.C. La línea quebrada, sin embargo, la vemos representada mayoritariamente a lo largo del siglo III d.C.

Por otra parte contamos con los datos que la arqueología ha suministrado sobre la historia de Complutum, que a su vez pueden ser indicativos para definir la cronología de nuestro mosaico. Tanto los edificios públicos como las casas privadas denotan un renacer generalizado que se fecha a partir de finales del siglo III d.C., prolongándose esta prosperidad a lo largo de la siguiente centuria.

Por lo tanto, tomando en cuenta los paralelos iconográficos anteriormente descritos y la realidad arqueológica del entorno, fechamos nuestro mosaico a finales del siglo III d.C. o principios del siglo IV d.C.

Otro aspecto importante es la definición de la escuela que ha producido el emblema. Tanto la temática como los mate- riales nos hablan de dos manos o dos grupos distintos en la ejecución del mosaico, pues mientras que el campo geométrico tiene relaciones conceptuales con la musivaria complutense e inspiraciones claras en el ámbito emeritense, el emblema es en cambio una pieza de origen inequívocamente africano, que se relaciona con un género y unos cartones muy concretos, e incluso para la resolución de las gamas cromáticas se recurre a mármoles importados del África Proconsular. Es cierto que otros mosaicos hispanos se sirven de estas mismas temáticas, y no hay razones técnicas que impidan suponer que un artesano hispánico fuera el autor del emblema. Sin embargo, la utilización de materiales importados, en concreto el verde tunecino empleado en los peces, da un voto a favor de la actuación de un taller procedente del Norte de África.

El deseo de remitirse a lo africano y de crear un ambiente lúdico y exótico parece ser muy fuerte entre los propietarios del edificio, ya que además de introducir una decoración acorde con este gusto, se recurre a instalar un avidario con especies de aquellas provincias. En este sentido hay que entender la presencia de los restos de un pelícano en el yacimiento".

Es sugestiva la hipótesis de un taller local, o al menos hispano, que manufacture todo el mosaico a excepción del emblema que se encargaría a un taller norteafricano. El estudio de la inscripción abre además, como se verá más adelante, interesantes posibilidades para la resolución de la «contratación» de este encargo y la identificación concreta del maestro que ejecutó nuestro mosaico.

\section{LA INSCRIPCIÓN}

\section{1. Edición del texto.}

\section{ANNIORVM (hédera) HIPPOLYTVS TESSELLAV[IT]}

\section{III.2. Descripción de la inscripción (fig. 10, lám. 12).}

El texto ocupa por completo el lateral derecho del emblema del mosaico (desde el punto de vista del espectador de la escena musiva), en su parte más exterior. Está enmarcado por una triple hilera de teselas de desigual anchura, de color (de exterior a interior) negro, «beige», negro.

El rectángulo que encierra la inscripción (de unas medidas de $244 \times 28 \mathrm{~cm}$ ) representa (ilusión realizada también con teselas) una tabula ansata, las asas de la cual (jsólo se nos ha

\footnotetext{
"HERNANDEZ CARRASQUILLA, 1991. Los estudios completos de la fauna del yacimiento están aún por concluirse y este dato proviene del análisis, ya terminado, de las aves. El pelícano no es, en ningún caso, una especie autóctona de Hispania, por lo que hay que pensar en una importación.
} 
conservado la izquierda!) estaban formadas por teselas de color rojo, ribeteadas por teselas negras.

El campo epigráfico conservado (delimitado por la distancia entre la primera y última letra conservadas) mide $25 \mathrm{~cm}$ y las letras tienen una altura mínima de $15 \mathrm{~cm}$ y máxima de 19 $\mathrm{cm}$. La separación entre letras es mínima (si exceptuamos la hédera), formando casi una scriptio continua. Las teselas que las componen son también negras, mientras que la hédera (con la cola apuntando hacia arriba) está realizada con teselas de color rojizo.

El tipo de la letra es la capital cuadrada, con unos trazos muy bien definidos y verticales para lo que suelen ser las inscripciones musivas hispanas. Sólo sobresale ligeramente de la caja de escritura el trazo inferior de la L (ligeramente inclinado hacia abajo) y el superior de la $T$ de Hippolytus. Por lo demás, la escritura es muy regular y podría fecharse sin mayores problemas (pero tampoco sin mayores precisiones) entre los siglos II a IV d.C.

\section{COMENTARIO DE LA INSCRIPCIÓN.}

\section{1. El Genitivo Plural.}

IV. 1.I. Tenemos algunos paralelos de uso del Gen. (por desgracia, siempre en $\mathrm{Sg}$.) en inscripciones musivas griegas anteriores a la nuestra.

- Donderer A 34:

\section{IIU}

Se trata de un pavimento geométrico que representa el laberinto, encontrado en La Mas Foulc (Francia) y fechado en el siglo I a.C. El Gen., en este caso Sg., sustantivado por el artículo determina, como en nuestro texto, a un sustantivo nombre de persona en Nom., funcionando como Suj. de un verbo de «acción musiva» ( $\varepsilon \pi 0 \varepsilon l=f e c i t$ ). El Gen. indica una relación de posesión respecto del sustantivo determinado, que puede ser interpretada como 1. Pítico es el esclavo de Antíoco (difícil para Donderer que un esclavo pertenezca a un Griego en la Galia del siglo I a.C.) o 2. Pítico es hijo de Antíoco (posibilidad aceptada -DONDERER:47-).

- Donderer A 28:

\section{[ET']A TA $\Theta \Omega$. NEIKIA $\triangle \triangle I O N U \triangle I O U \triangle O U L O \Sigma$ EПOIE}

Es este un mosaico con una escena atlética, procedente de las termas de Tyndaris (Sichia, Italia) y fechable en la segunda mitad del siglo II d.C. En este caso, muy parecido al anterior, también se indica la firma de un mosaista, aunque la ausencia de sustantivación del Gen. nos indica el probable origen esclavo del artesano.

IV.1.2. Los casos de Gen. Pl. en las inscripciones musivas latinas son muy escasos.

- Donderer A 59:
Fl(aviorum) Iustiniani et Sabini [op]us

Mosaico perdido procedente de Cherchel (Algeria) y fechable (con dudas) en el siglo IV d.C.

Parece claro (siempre que se acepte la restitución [op]us) que se trata, también aquí, de una firma doble de artistas. Según Donderer, se trataría de los hermanos Iustinianus y Sabinus que pertenecerían a una gens Flavia. Donderer justifica esta interpretación del Gen. Pl. porque son dos los firmantes, pero no conviene olvidar que nuestro texto presenta a un individuo aislado, determinado también por un Gen. Pl. (el presunto paralelo, por tanto, lo es menos). De lo que no hay dudas es de que se trata, otra vez, de los ejecutores del mosaico.

\section{- Donderer A 72:}

\section{Masuri -in praedi(i)s Laberiorum Laberiani et Paulini-Masuri}

Mosaico de tema órfico procedente de Oudna (Túnez) y fechable en el siglo III d.C.

Aunque Donderer no comenta nada, parece que el nombre del mosaista es aquí Masurius (también en Gen., aunque Sg.), mientras que el Gen. Pl. no puede tampoco ser paralelo de nuestro Anniorum porque determina a praedi(i)s, como Gen. posesivo indicando propietario, y no a un nombre propio.

- Donderer C 19:

\section{Domus Aripporum et / Vlpiorum Vibiorum / felix}

Mosaico procedente de Roma (Italia), de decoración geométrica, fechable en la primera mitad del siglo III d.C.

Tampoco es un paralelo para el nuestro (aunque en este caso se encuentra también en una tabula ansata) porque el Gen. Pl. determina a domus, en el contexto de una fórmula para desear la felicidad de los propietarios de la misma

Conviene indicar, por fin, que en nuestra zona específica de estudio, Hispania, la aparición de un Gen. Pl. indicando un gentilicio y determinando a un nombre personal en Nom. es un unicum: el primer caso que conocemos.

IV.1.3. En cambio, los Gen. Sg. son algo más frecuentes y, aunque no suelen determinar a un nombre de persona, sí son gentilicios (comparables, por tanto, a los Anios de nuestra inscripción) que identifican al taller que ha confeccionado el mosaico.

- Gómez Pallares 1.7.:

\section{EX OFFICIN[A] IVL[II] PRVD[ENTIS?]}

Mosaico conservado in situ en la villa de Carranque (Toledo) y fechable en los siglos III-IV d.C.

- Gómez Pallares 1.8.:

$$
\text { EX OFICINA MA[---]NI }
$$

Mosaico conservado in situ en la villa de Carranque (Toledo) y fechable en los siglos III-IV d.C.

- Gómez Pallares 1.11.:

\section{EX OF/FICINA FELICES}


Mosaico procedente de la llamada Villa Vitalis de Tossa de Mar (Girona) y fechable en el siglo IV d.C.

- Gómez Pallares 1.12.:

\section{EX OFFICINA / ANNIPONI}

Mosaico procedente de Mérida (Badajoz) y fechable con dudas en el siglo IV d.C.

- Gómez Pallares 1.13.:

\section{EX OFFICINA / DEXTERI}

Mosaico procedente de Valdelacalzada (Badajoz) y fechable (sin más precisiones) en el Bajo Imperio (¿siglo IV d.C.?).

IV.1.4. En una inscripción musiva, hasta donde nosotros conocemos, el Gen. siempre indica posesión y el tipo o calidad de ésta viene indicado por el sustantivo al que determina. Si excluimos la posibilidad de una filiación estricta (no tendría demasiado sentido que Hipólito fuera hijo stricto sensu de diversos Anios), nuestro Gen. Pl. sólo podría querer indicar que «Hipólito pertenece a la gens Annia», pero no como hijo de un miembro de la misma, sino con algún otro tipo de relación. Por otra parte, conviene recordar que el uso general del Gen. en las inscripciones musivas (cuando el contexto o la palabra determinada no nos indican lo contrario) es el de darnos a conocer el nombre del ejecutor del mosaico o alguien relacionado con esa operación.

\section{IV.2. El gentilicio Annius.}

Annius es un nomen de probable origen osco (LEJEUNE y LEJEUNE, l'Onomastique: 35-41), que se extendió con cierta rapidez por los dominios de Roma (ALFOLDY, l'Onomastique: 256; CHASTAGNOL, L'Onomastique: 329; SOLIN y SALOMIES, 1988, s.v. Annius), unas veces con geminación, otras sin ella (SCHULZE, 1966: 122). En Hispania, su aceptación y propagación no desmerece del resto del Imperio Romano (ALBERTOS, 1966: 27; PALOMAR, 1957:146). En cuanto a su distribución, CIL II nos proporciona algunos casos aislados ${ }^{6}$, pero la única «concentración» más o menos significativa se localiza en la capital del Conventus Tarraconensis, Tarraco. En ella encontramos a diversos Annii relacionados con una actividad «artesana» como es la fabricación de cerámica. Bajo los títulos de CIL II4970 (in vasis ex terra rubra factis imis a parte exteriore vel interiore) se recogen los nombres de ANII (s.n. 22), ANI OFIC (s.n. 23), SEX. ANN (s.n. 26, 171, 454), C.ANNIVS (s.n. 155, 242), L.ANNIVS (s.n. 67, 71), Q.ANNIVS (s.n. 438), [---]ANNIVS (s.n. 482)...

\footnotetext{
'Por ejemplo, CIL II 1290, Q.Annius, procedente de Utrera (Baetica) o CIL II 2343, G.Annius Annianus, procedente de Fuenteovejuna (Baetica).
}

Por su parte, RIT 6 recoge un Philodamus Anni Publi ser$v u s^{7}$ (¿republicano tardío?), mientras que en RIT $205=C L$ II 4143 encontramos una inscripción dedicada al speculator Q.Annius Aper (finales del siglo I-primera mitad del siglo II d.C.), dedicada por, entre otros, un L.Annius Vitaliss.

Además de los ya citados, RIT recoge la existencia de otros Annii, nacidos en distintas partes de la Península Ibérica, pero que fueron a morir a Tarraco, v.g., RIT $254=$ CIL II 4191, L.Annius Cantaber, procedente de Segobriga (fechable entre el 120 y el 180 d.C.), RIT $330=$ CIL II 4192, C.Annius Flavus, procedente de Iuliobriga (fechable entre Hadriano y los Antoninos). Todavía cita RIT otro Anio, Annias Leonas (RIT $506=C I L$ II 4331), en un epitafio fechable en la segunda mitad del siglo III d.C., dedicado por una madre a su hijo de 27 años.

IV.2.1. De la información aducida podemos deducir que los Annii son conocidos en Hispania y, sobre todo, en Tarraco, desde el final de la República hasta los siglos III-IV d.C. y que la mayoría de los individuos que llevan este nomen son hombres libres con una posición más o menos solvente en la sociedad de su tiempo. La mayoría de ellos, además (aunque aquí la cantidad no es relevante), se dedican a la producción cerámica (esto ya es más significativo).

\section{IV.3. EI Nominativo Singular.}

\section{IV.3.1. Nom. como Suj. de un V.}

Dado el texto que estamos estudiando, no tiene demasiado sentido hablar de Nom. aislados en inscripciones musivas ni de Nom. Suj. sin más, sino de Nom. Suj. de un V. que indique algún tipo de acción relacionada con el mosaico (lo que llamamos V. de «acción musiva»), sea esta de tipo activo transitivo o de tipo causativo factitivo, porque eso es lo que, en principio, se puede interpretar en nuestro texto (Hippolytus tesselavit).

\section{IV.3.1.1. Nom. como Suj. de tessellare.}

Como ya sucedía con el nomen Annius (en Gen. Pl. determinando a un sustantivo), también es un unicum en Hispania la aparición de nuestro texto, con un nombre de persona como Suj. del V. tessellare. Hay, en cambio, algunos casos paralelos en el resto del Imperio Romano.

\footnotetext{
${ }^{7}$ Indica ALFÖLDY, p.5, que «Annii sind in Tarraco auch aus späterer Zeit bekannt.

* Indica ALFÖLDY, p.115, que «Q.Annlius Aper. . .und L.Annius Vitalis führten einen in Spanien häufigen Gentilnahmen».
} 
- Donderer C 14:

\section{Dignis dig/na, patri Arge/ntio coronam. / Benenatus tes(s)el(l)avit}

Mosaico perdido procedente de Seriana (Algeria), del siglo VI d.C.(?).

- Donderer C 23:

Fl(avius) Inno/centius Num(idicus?) / pro . salute / sua suorum/que omnium / tessel(l)avit

Mosaico procedente de Setif (Argelia), perdido pero fechable en el siglo IV d.C.

- Donderer C 29:

\section{C(aius) Libarnius / Tusculanus / tesselavit grados /} subgrundam fecit

Mosaico perdido procedente de Roma, situado (sin más precisiones) en la Antiguedad tardía.

- Donderer C 37:

[.....]s Titian[....] / tessella[vi]t Caecilius / Caec[.....]

Mosaico procedente de Cherchel (Algeria), fechable en la primera mitad del siglo IV d.C.

Del estudio de estos casos deduce Donderer (p.30) que el uso de tessellare en pavimentos indica que quien se identifica como Suj. de este V. es el donante del monumento, es decir, quien paga el mismo. Por tanto, según Donderer, se rompe la «ecuación» tesserarius (tessellarius, tessellator $)=$ «ejecutor material de un mosaico $\$>$ tessellare $=$ «acción activa que realiza el tesserarius», para otorgar a este V. un valor causativo/factitivo del tipo «hacer teselar» (si se nos permite el cultismo), en vez de «teselar». Si nos fijamos en las inscripciones recogidas por Donderer y en su contenido, parece lógico deducir de ellas el valor causativo de tessellare: en todas se hace explícita una donación del pavimento (menos en la muy fragmentaria C 37) y en todas ellas (menos en la más tardía $C$ 14) intervienen tria nomina. Notemos que ninguna de las dos circunstancias concurre en nuestro texto, desconocido por Donderer por razones obvias.

Todavía más. Fijémonos en C 29, inscripción importante para nuestra argumentación, porque en ella encontramos dos V. distintos de «acción musiva», tessellavit y fecit. Habrá que admitir aquí, según el contenido fijado por Donderer, que ambos tienen un valor causativo («ha hecho teselar» $y$ «ha hecho construir»), aunque el segundo de ellos nunca (en otros contextos, como veremos más adelante) ha sido interpretado así. Habrá que admitir, por tanto, a la luz de esta inscripción, que no siempre se utiliza un mismo V. de la misma manera y que, si fecit es aquí utilizado con un valor causativo (cuando

\footnotetext{
9 Vid., por ejemplo, DONDERER A 56: Felix tesserarius fecit, mosaico de Falerone (Italia), fechable en el siglo IV d.C., donde Felix es identificado sin ninguna duda como el artesano ejecutor del mosaico.
}

siempre suele suceder que tiene un normal valor activo), también será posible (si el contexto lo permite) que tessellare deje de ser causativo en alguna ocasión.

\section{IV.3.1.2. Nom. como Suj. de V. análogos a tessellare.}

Donderer aduce alguna otra inscripción para reforzar su interpretación causativa de tessellare, con V. o perífrasis que equivaldrían a la utilización de ese $\mathrm{V}$.

- AE 1917 18, 27 + AE 1920 21:

[PAVIMENTVM TESSELLIS ET PARIETES MARMORIB(VS) EXORNAVIT

Inscripción procedente de

La perífrasis pavimentum tessellis exornavit equivaldría a tessellare. No tenemos nada que objetar a tal interpretación, aunque la inscripción no puede ser comparada con el texto de la nuestra.

- Gómez Pallarés, Esbozo 71 : C.CAL.PVR.NI.VS[---]NVS.ET.GVI.BI.VS. QVIN.TI.LI.A.NVS.ET.L.ATTI[---]S.ET.MVER. RIVS.CE.MI.NVS.SOLVM TES.SELLASIQVE D(e) S(uo) STRAVER]VNT.ET.DO.NA.RVNT

Mosaico procedente de Faro (Portugal) y fechable en la segunda mitad del siglo III d.C. Aquí, tessellas stravere equivaldría a tessellare y, sin ninguna duda dado el carácter dedicatorio de la inscripción, tendría un valor causativo.

Se deduce de estas inscripciones que en los textos musivos que conocemos se identifica siempre con claridad (siempre que su estado lo permite) a quien realiza la donación y, por tanto, el desembolso económico, bien sea a través de su nombre, posición y cargo, bien a través de la fórmula utilizada para indicarlo. Parece lógico, por tanto, deducir que si otorgáramos a nuestro tessellavit el valor que propone, siempre y sin variación, Donderer, Hippolytus sería quien, de una forma un tanto anónima (visto el modus operandi de todas las inscripciones hasta ahora aducidas) habría «hecho teselar» y, por tanto, pagado, el pavimento complutense.

Recoge Donderer otra inscripción muy interesante para nuestra argumentación.

\section{- Donderer A 85:}

\section{Sempron(ius) / [s]travit}

Procedente de Alejandría (Egipto) y fechable con dudas en el siglo III d.C.

La modestia del texto así como su posición secundaria en el mosaico donde se encontró (hoy desaparecido), llevan a Donderer a romper la «ecuación» stravere = tessellare, con valor causativo ambos, que había enunciado para la inscripción de Faro (Portugal), vid. supra, y a postular que, aquí, Sempronius es una firma de artesano y no de donante. Ni que decir tiene que el texto de A 85 es perfectamente comparable al nuestro (falta tan sólo el Gen. Pl.) y que si el propio Donderer 
interpreta aquí stravere con un valor activo normal, también podríamos nosotros plantear la hipótesis de que un Nom. como Suj. de tessellare pudiera llevar a una interpretación no causativa de tal V. (por ejemplo, en nuestra inscripción).

\section{IV.3. 1.3. Nom. como Suj. de otros V. de «acción musiva».}

Para poder completar la documentación de nuestra argumentación, conviene ahora citar algunos casos en que, tan claramente como en los ejemplos de Donderer se ve el valor causativo de tessellare, podamos comprobar el valor activo normal de otros V. musivos por excelencia, v.g. facio.

- Gómez Pallarès 1.3.:

\section{C(olonia) A(ugusta) E(merita) F(ecerunt)}

\section{SELEVCVS . ET . ANTHVS}

Mosaico procedente de Mérida (Badajoz) y fechable en la segunda mitad del siglo II d.C.

\section{- Gómez Pallarès 1.5.:}

\section{CECILIANVS . FICET}

Mosaico procedente de la Torre de Bel-loch (Girona) y fechable en el siglo III d.C.

- Gómez Pallarès 1.8.:

\section{EX OFICINA MA[---]NI / PINGIT HIRINIVS}

Procedente de la villa de Carranque (Toledo) y fechable en los siglos III-IV d.C.

Donderer A 48:

\section{Aristo fac(it)}

Mosaico procedente de Roma (Italia) y fechable en el siglo II d.C.

- Donderer A 49:

\section{Attilus fecit}

Mosaico procedente de Oberweningen (Suiza) y fechable en la segunda mitad del siglo II d.C.

- Donderer A 56:

\section{Felix tesserarius fecit}

Mosaico procedente de Falerona (Italia) y fechable en el siglo IV d.C.

- Donderer A 60:

\section{Her[ma]nus facit}

Procedente de Cherchel (Algeria) y fechable con dudas en el siglo II d.C.

- Donderer A 73:

\section{Modicu $<s>f(e c i t)$}

Mosaico procedente de Bavay (Francia) y fechable en el siglo II d.C.

Donderer A 74:

\section{Monnus fecit}

Mosaico procedente de Trier (Alemania) y fechable en la mitad del siglo III d.C.

A pesar del claro valor no causativo (que nadie pone en duda) del verbo facio en este tipo de inscripciones (nótese la variedad de sus procedencias y cronologías), también podemos aducir algunos casos en que, por el contexto y contenido de la inscripción, facio se interpreta causativamente.

- Donderer C 24:

Ave Quartila, da bis. Salv(u)s sis, Gra(te). / Gratus architec(tu)s p (ecunia) s(ua) ego felix [fe]ci

Mosaico procedente de Pompeya (Italia), perdido, fechable entre los siglos I a, y d.C.

- Donderer C 27:

\section{Gen(io) Thac(aratensi) fel(iciter) P(ublius) Iulius Faustus fecit}

Mosaico procedente de Ain Touta (Argelia) y fechable en el siglo III d.C.

Desde nuestro punto de vista, los dos son claros ejemplos de que facio puede también utilizarse con un valor causativo (por los nombres, por el carácter dedicatorio de $\mathrm{C} 27$, por la fórmula p(ecunia) s(ua) de C 24, etc.) Podemos todavía ir algo más allá y encontrar un ejemplo de ese $\mathrm{V}$., en una inscripción musiva de extrema sencillez, también con valor causativo.

\section{Donderer C 34:}

\section{[Pro]clus / fecit m(iles) c(ohortis) s(ua) i(mpensa)}

Procedente de Ostia (Italia) (en la «Caserna dei vigili»), fechable en el siglo III d.C., se trata de un mosaico en blanco y negro, con la única decoración de una crátera central y la inscripción en un lateral.

A partir de estos últimos ejemplos, queda claro que, sea cual sea el origen, profesión, estado económico del dedicante y destino final de mosaico e inscripción, quien hace el esfuerzo económico se preocupa por hacerlo saber explícitamente (sea cual sea el sistema que utilice para hacerlo e independientemente de la calidad, tamaño, posición, etc., de la inscripción respecto del mosaico: C 24 y C 27 son antitéticas, en este sentido, respecto de $\mathrm{C} 34 \mathrm{y}$, en cambio, todas persiguen lo mismo).

La conclusión a que llegamos en este apartado es clara: de la misma manera que facio, como V. de «acción musiva», puede ser interpretado como V. activo normal o como V. causativo, según el texto y contexto en que se encuentre (negando, por tanto, los ejemplos precedentes un solo valor «de aplicación universal» para ese V.), también tessellare, como V. de las mismas características, debiera poder interpretarse como activo o como causativo, según lo demanden las circunstancias de su contexto.

\section{IV.4. El nombre personal Hippolytus.}

El nombre Hippolytus goza de una cierta popularidad en Roma. H.Solin (1982: s.v. Hippolytus) lo documenta en 37 ocasiones, pero sus conclusiones no aportan nada significativo a este trabajo, pues 31 de sus 37 casos son incerti (más un senador y cinco esclavos o libertos). De estos incerti llama especialmente la atención CIL VI 34407, donde figura como 
dedicante un P.Annius Hippolytus. No creemos que la explicación de nuestro Hippolytus vaya por ese camino, pues la relación que se establece entre Annius e Hippolytus en nuestro texto no es a través de un tria o duo nomina, sino de un Gen. $\mathrm{Pl}$., que implica algún tipo de posesión de los Anios respecto de Hipólito.

Sí interesa remarcar, en cambio, que se trata de un unum nomen de procedencia griega y que nada (ni la decoración musiva ni el texto ni el contexto) hace suponer que estemos delante de un uso cristiano del mismo ${ }^{10}$. Cierto tipo de nombres empieza a ser especialmente utilizado por cristianos a partir de la popularidad que pueda alcanzar alguno de sus usuarios", pero no son cristianos en su origen ${ }^{12}$.

En Hispania, hasta donde nosotros conocemos, tenemos un Hippolytus documentado. Se trata de CIL II $4319=$ RIT 393, donde encontramos una inscripción dedicada por L.Aemil.Euhodus a su compañero liberto L.Aemil. Hippolytus (...) q(ui) fuit natione Graecus. Es interesante remarcar que este Hipólito procede de Tarragona, aunque se trate de un liberto que utiliza un tria nomina (no es este nuestro caso, al menos por lo que hace al tria nomina).

Hay que destacar también que se trata de inscripciones tardías (tanto el caso de RIT como el nuestro), puesto que el nomen Hippolytus es utilizado como cognomen (en RIT esto es evidente). I.Kajanto analizó hace tiempo la cuestión ${ }^{13}$, para llegar a la conclusión de que «a consequence of the lessening of the importance of the nomen was the extensive use of nomina as cognomina during the Later Empire» (KAJANTO, 1963: 18). Es importante remarcar también la idea que se deduce del estudio de Kajanto (pensamos sin duda en nuestra argumentación), cuando nos indica (1963: p.20, nota 1) que «there are not a few cases in which freedmen have a Latin nomen as a cognomen, e.g. CIL VI 7816, T. Quinctius A.l. Laelius and CIL VI 15648, T. Cl. Aug. lib. Petronius ${ }^{14}$, may have been called Laelius and Petronius as slaves».

No pretendemos avanzar la hipótesis de una identificación entre L.Aemil. Hippolytus (¡él era un educador!) y nuestro

\footnotetext{
${ }^{10}$ Vid. MARROU, LOnomastique, p.435, donde afirma que «par exemple, Hippolyte n'a rien de spécifiquement chrétien».

"En el caso que nos ocupa, puede que esta popularidad provenga en parte de Hipólito de Roma, muerto en Cerdeña hacia el 235-236, adversario del papa Calixto I y conocido exégeta de las escrituras. Fue venerado como santo.

${ }^{12}$ Vid. PIETRI, L 'Onomastique, 440, donde dice: «dans la plupart de grands cimétieres, I'usage chrétien consacre d'autres noms, sans leur donner la popularité de Laurent ou de Pierre...énumerons...Hippolytus».

${ }^{13}$ Cf. KAJANTO, 1963, pp. 18-20, en un apartado de introducción general -no habla tan sólo de textos cristianos- titulado «The Use of Nomina as Cognomina».

${ }^{14}$ Añadiriamos aquí, por ejemplo, nuestro CIL II 4319.
}

Hippolytus, pero sí argumentar en favor de la condición de esclavo o liberto de nuestro personaje en relación, claro está, con el Gen. Pl. que le determina en la inscripción.

En un apartado anterior, aducíamos algún material hispano de Nom. como Suj. de un V. de «acción musiva», pero nos fijábamos tan sólo en el significado de ese V. Volvamos brevemente a él, pero contemplando los ejemplos per se y no en función de un V. Partiendo de la base de que, también en este caso, nuestra inscripción es un unicum (no existe otro Hippolytus en inscripciones musivas de Hispania), los textos de que disponemos son los siguientes.

- Gómez Pallarès, 1.3.:

\section{C.A.E.F. SELEVCVS . ET . ANTHVS}

Procedente de Mérida (Badajoz) y fechable en la segunda mitad del siglo II d.C.

- Gómez Pallarès 1.5.:

\section{CECILIANUS . FICET.}

Procedente de la Torre de Bel-loch (Girona) y fechable en el siglo III d.C.

- Gómez Pallarès 1.6.:

\section{PARTENOS F}

Procedente de Mérida (Badajoz) y fechable en el siglo III d.C.

- Gómez Pallarès 1.8.:

\section{PINGIT HIRINIVS}

Procedente de Carranque (Toledo) y fechable en los siglos III-IV d.C.

- Gómez Pallarès 1.10:

\section{MAS/CEL//MARCIA/NVS}

Procedente de Italica (Santiponce, Sevilla) y fechable en el siglo IV d.C.

- Gómez Pallarès 3.3.:

\section{VALERIVS PERFECIT}

Mosaico procedente de Igabrum (Cabra, Córdoba), fechable en los siglos III-IV d.C.

Todos los casos de que disponemos en Hispania (hablamos evidentemente de epigrafía musiva) son unum nomen aislados (algunos funcionando como nomina = cognomina, otros directamente cognomina solos) y al menos tres de ellos son de procedencia griega (Seleucus, Anthus y Partenos). Todos ellos (menos el Valerius citado en último lugar) han sido identificados como artesanos que dejaron su firma sobre el mosaico que ellos mismos construyeron o contribuyeron a construir.

\section{CONCLUSIONES. PROPUESTA DE INTERPRETACION DE LA INSCRIPCION.5}

Sin necesidad de repetir toda la argumentación que hemos desarrollado en las páginas anteriores, los puntos fundamentales sobre los que basamos nuestra interpretación son los siguientes: 
A. La relación del Gen. PI. con el Nom. Sg. implica posesión de algún tipo (pasada o presente) y no filiación.

B. El Gen. Pl. indica un gentilicio muy popular en Hispania, pero que en Tarraco tiene una especial incidencia en la dedicación a las labores artesanas.

C. El Nom. como Suj. de un V. de «acción musiva» puede querer indicar tanto quien ha hecho materialmente el mosaico como quien lo ha hecho hacer (la posición, tamaño de la inscripción, etc., respecto del motivo figurado del mosaico no son datos definitivos para inclinarse por ninguna interpretación en concreto).

D. El V. tessellare, como V. de «acción musiva» comparable a stravere o facere, puede ser interpretado con un valor causativo (valor habitual en él) o con un valor activo transitivo normal, dependiendo tal interpretación del contexto en que se encuentre (como ya hemos visto que puede suceder en los demás $\mathrm{V}$. analizados).

E. El Nom. Suj. de ese V. denota un individuo de origen griego, no específicamente cristiano, que utiliza un unum nomen $=$ cognomen para ser identificado, además de verse determinado por un gentilicio en Gen. Pl.

Constatando además que la inscripción de Complutum es un unicum dentro del corpus de inscripciones musivas conocidas de Hispania, la interpretación que proponemos para ella es la siguiente:

«Hipólito, que pertenece a los Anios, ha teselado este mosaico».

Consideramos, por tanto, que:

A. Hipólito es esclavo o liberto de los Anios.

B. El ha realizado materialmente el mosaico.

No tenemos, en cambio, base documental suficiente para decir si Hipólito procede realmente de Tarraco o no; si su relación de posesión respecto de los citados Anios existe en virtud de su esclavitud pasada o todavía presente cuando construye el mosaico; qué tipo de relación «laboral» mantiene con ellos, si es que la mantiene (si los Anios, por ejemplo, le emplean en un taller musivario de su propiedad); si Hipólito es un artesano itinerante, que se ha desplazado de su «base de operaciones» o bien está establecido en Complutum; si, además de hacer el mosaico (o el emblema), ha contribuido en algo a los gastos generados por él (aunque como hemos visto, el tamaño de la inscripción no debe predeterminar una interpretación, tampoco es normal que un artesano, sin más, disponga de tanto espacio para firmar su obra) y, por tanto, ha «exigido» más espacio del habitual para ver «anunciado» su trabajo; etc. A partir de la argumentación e interpretación propuestas surgen éstas y otras muchas hipótesis de trabajo alrededor de esta inscripción musiva como objeto de estudio (a partir del análisis único del texto).

\section{CONCLUSIONES GENERALES}

La ejecución del mosaico de Hippolytus tuvo lugar en algún momento a finales del siglo III d.C. o principios del siglo IV d.C., en consonancia con los avatares que afectan a la ciudad romana de Complutum.

En el mosaico han intervenido dos manos o incluso dos talleres, uno del ámbito hispano en el campo geométrico y otro de formación norteafricana para la confección del emblema. Este pertenece a un género muy concreto, el de pesca, que se relaciona casi siempre con termas y fuentes y que tiene su pleno desarrollo en el África Proconsular.

Hippolytus es el maestro encargado de su ejecución, y sabemos que es un esclavo o liberto de la familia de los Anios.

Carecemos de base documental para afirmarlo, pero se puede hipotetizar con un origen tarraconense para esta familia. Es sugerente pensar en Hippolytus como en un maestro del Norte de África «contratado» por una poderosa familia hispana para cumplir un encargo concreto de unos clientes complutenses. Quizá el deseo de contar con un artista extranjero y la novedad de introducir en Complutum un mosaico totalmente africano han pesado mucho para permitir que, por el contrario de lo que es habitual, Hippolytus contase con un espacio grande para poder dejar su firma en la obra realizada.

Teorías, en todo caso de difícil confirmación, nos parecen interesantes para esclarecer el funcionamiento del negocio del mosaico, que aún permace oscuro en muchos puntos.

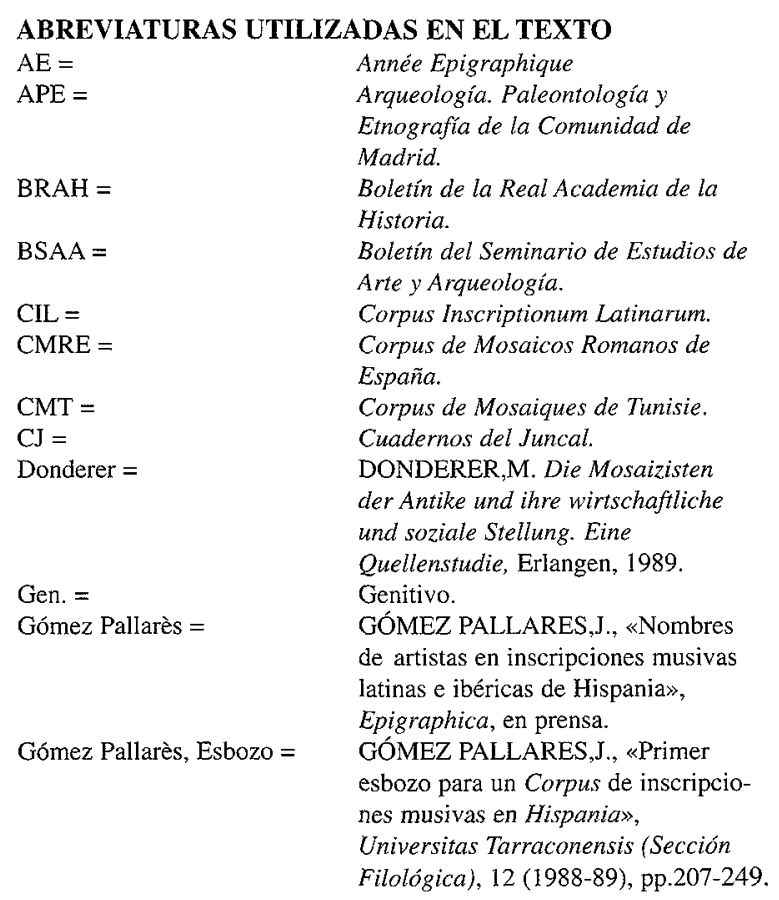


$\mathrm{IMB}=$

INAAT $=$

INAAT-EFR =

LMGR =

L'Onomastique $=$

Nom. $=$

PI. =

$\mathrm{RA}=$

$\mathrm{RG}=$

RIT $=$

$\mathrm{Sg} .=$

Suj.=

ThLL =

$\mathrm{V}=$

Inventario del Museo del Bardo.

Institute National dArcheologie et d'Art. Tunis.

Institute National dArcheologie et d'Art. Tunis. École Francaise de Rome. La mosaique gréco-romaine. Colloques Internationaux $d u$ Centre National de la RechercheScientifique.

L'Onomastique Latina. Colloque Internationale du CNRS, $\mathrm{n}^{\circ} 564$,

Paris, 1977.

Nominativo.

Plural.

Revista de Arqueología.

Revista Guimaraes.

ALFÖLDY,G., Die römische

Inschriften von Tarraco, Berlín, 1973.

Singular.

Sujeto.

Thesaurus Linguae Latinae.

Verbo.

\section{BIBLIOGRAFÍA}

ACUÑA CASTROVIEJO, F. (1972): «Los mosaicos de La Cigarrosa (Orense)». BSAA, 38, 1972.

ADAM, J.P. (1984): La construction romaine. Materiaux et techniques. Paris, 1984.

ALBERTOS FIRMAT, M.L. (1966): La onomástica personal primitiva de Hispania. Tarraconense y Bética, Salamanca, 1966.

ALFÖLDY, G.: «Die Personennamen in der römischen Provinz Noricum», l'Onomastique, pp.249-265.

ÁLVAREZ MARTíNEZ, J.M. (1990): Mosaicos romanos de Mérida. Nuevos hallazgos. Monografías Emeritenses, 4. Mérida, 1990

BALIL,A. (1958) «Consideraciones sobre el mosaico hispanorromano». R.G. 68. 1958.

BALL, A. (1960): «Arte helenístico en el Levante español: el mosaico con representación de peces hallado en Ampurias». BRAH. 146, Madrid, 1960.

BALIL,A. (1962-63): «Mosaico con escenas portuarias hallado en Toledo».Homenaje al profesor Cayetano de Mergelina. Murcia, 1962-63, pp. 123-127.

BALIL,A. «Sobre los mosaicos romanos de Galicia: identificación de un taller musivario», $L M G R$, II.

BALIL, A. (1969): «Un mosaico nilótico de la Bética». CTEE HAR, XIII, 1969, pp.103-113.

BALIL, A. y MONDELO, R. (1985):«Un mosaico con representación de peces hallado en las proximidades de Tarragona». BSAA, LI, 1985.

BLANCO FREIJEIRO,A. (1978): Mosaicos romanos de Itálica (I). CMRE, fasc.II, Madrid, 1978.

BLÁZQUEZ MARTÍNEZ, J.M. (1981): Mosaicos romanos de Córdoba, Jaen y Málaga. CMRE, fasc.III, Madrid, 1981

BLÁZQUEZ MARTÍNEZ ,J.M. (1982): Mosaicos romanos de Sevilla, Granada Cádiz y Murcia. CMRE, fasc.IV, Madrid, 1982.

BLÁZQUEZ MARTÍNEZ, J.M. y MEZQUIRIZ, M.A. (1985): Mosaicos romanos de Navarra, CMRE fasc.7, Madrid, 1985.

BLÁZQUEZ, J.M. y ORTEGO,T. (1983): Mosaicos romanos de Soria, CMRE, fasc. VI, Madrid, 1983.

BRODRIBB,G. (1987): Roman brick and tile. Alan Sutton Publishing. Gloucester, 1987.
Corpus de Mosaiques de Tunisie. Vol.II. fasc.3. Thuburbo Maius. INAAT. Túnez,

CHASTAGNOL, A.: «L'Onomastique de l'album de Timgad»,L' Onomastique, pp. $325-337$.

CHIC GARCIA, G. ([993): «La navegación fluvial en época romana». $R A, 142$. Madrid, 1993.

DUNBABIN,K.M.D. (1978): The mosaics of Roman North Africa. Studies in Iconography and Patronage. Clarendon Press. Oxford, 1978.

DUVAL, P.M. (1949): «La forme des navires romaines d'apres la mosaique d'Althiburus». MAH, LXI. Paris, 1949, pp. 119-149.

FERNÁNDEZ CASTRO,M.C. (1982): Villas romanas en Hispania. Ministerio de Cultura, Madrid, 1982

FERNÁNDEZ-GALIANO RUIZ,D. (1984): Complutun II. Mosaicos. EAE, 138. Madrid, 1984.

FOUCHER, L. (1957): Navires et barques figures sur des mosaiques decouvertes a Sousse et aux environs. Notes et documents, XV, INAAT, Túnez, 1957.

FOUCHER, L. (1960): IM. feuille $n^{\circ} 57$ de l'Atlas Archéologique. Sousse. INAAT, 1960.

GROSSE,A. (1947): Fontes Hispaniae Antiquae, fasc.IX, «Las fuentes de época visigoda y bizantina», Barcelona, 1947.

GULLINI, G (1956): I mosaici di Palestrina. Roma, 1956.

HERNÁNDEZ CARRASQUILLA, F. (1991): Las aves de la villa romana de Hippolytus. Campaña 1990-91. (Inédito). Madrid, 1991.

KAJANTO, I. (1963): Onomastic Studies in the early Christian Inscriptions of Rome and Carthage, Helsinki, 1963.

LEJEUNE, A. y M.: «La Romanisation des Anthroponymes indigenes d'Italie», L'Onomastique, pp.35-41.

MARROU, H.-I.: «Problemes génneraux de l'onomastique chrétienne», L'Onomastique, pp.431-435.

MÉNDEZ MADARIAGA,A. y RASCÓN MARQUES,S. (1989a): Los visigodos en Alcalá de Henares. CJ, 1. Alcalá de Henares, 1989.

MÉNDEZ MADARIAGA,A. y RASCÓN MARQUES,S. (1989b): «La villa romana del Val. Alcalá de Henares». RA. n'101. 1989.

PALOMAR LAPESA, M. (1957): La onomástica personal pre-latina de la antigua Lusitania, Salamanca, 1957

PALOMBI, P (1980): La fauna marina nei mosaici e nei dipinti pompeiani. Nápoles, 1980.

PERNICE,E. (1936): Die hellenistiche Kunst in Pompeii. Pavimente und figurliche Mosaiken. Berlín, 1936.

PICARD, G. et alii (1977):Recherches Archeologiques Franco-Tunisienes a Mactar. I. La maison de Venus. Paris.INAAT-EFR, 1977.

PIETRI, CH: «Remarques sur l'onomastique chrétienne de Rome», L'Onomastique, pp.437-445.

RASCÓN MARQUÉS, S, y MÉNDEZ MADARIAGA, A. (en prensa) Complutum Ill. La ciudad y los edificios públicos. APE.

SANZ GAMO,R. (1987a): «Mosaicos romanos del Camino viejo de las sepulturas (Balazote, Albacete)». Al Basit, 21, Albacete, 1987.

SANZ GAMO,R. (1987b): «Notas sobre los mosaicos romanos de Balazote (Albacete)». Caesaraugusta, 64, Zaragoza, 1987.

SCHULZE, W. (1966): Zur Geschichte lateinischer Eigennamen, Berlin-Zurich Dublin, 1966.

SOLIN, H. (1982): Die griechische Personennamen in Rom. Ein Namenbuch, Berlin-New York, 1982.

SOLIN, H. y SALOMIES, O. (1988): Repertorium nominum gentilium et cognominum latinorum, Hildesheim-Zurich-New York, 1988.

YACOUB, M. (1970): Le Museé du Bardo. INAAT, Túnez, 1970.

NOTA FINAL. Encontrándose en prensa este artículo han concluido las excavaciones arqueológicas del edificio en que se encontró el mosaico objeto de nuestro estudio. Un análisis pormenorizado del mismo nos permite ahora afirmar que el complejo que hemos llamado la Casa o las Termas de Hippolytus no es sino la sede de un collegium iuvenum complutense, siendo la también complutense familia de los Annii la patrona del mismo. Todo ello altera en cierta medida la lectura e interpretación del mosaico, y en cualquier caso remitimos a los interesados a la lectura de la memoria correspondiente, que ahora se encuentra en preparación. 